\title{
El bizutage: ritual y reproducción social en la enseñanza superior francesa
}

\author{
GABRIELLE LEFLAIVE \\ Dpto. de Antropología Social. \\ Universidad Complutense. Madrid
}

\section{RESUMEN}

El artículo es un estudio del bizutage, conjunto ritualizado de novatadas practicado hasta hace poco en un sector específico de la enseñanza superior francesa: el de las "prépas" y las "Grandes Ecoles". Tras analizar las características de este sistema de enseñanza y su historia, y tras una interpretación de los elementos simbólicos y sociales del bizutage -espacio, tiempo, actores, lenguaje, pruebas y castigos-, se muestra que el ritual constituía una verdadera iniciación con sus tres partes bien definidas: separación, margen y agregación; una iniciación que permitía la reproducción social de unas relaciones de dominación basadas en los títulos de las Grandes Ecoles, la perpetuación de una elite y la creación de una "distinción". El debate en torno a la reciente prohibición del bizutage revela cómo se oculta la verdadera naturaleza del sistema de enseñanza de las Grandes Ecoles - es decir, su elitismo social- al presentar la selección que lo caracteriza como basada en criterios "naturales" de capacidad intelectual y esfuerzo individual.

Palabras clave: Ritos de iniciación, Novatadas, Ritual, Reproducción social, Enseñanza superior francesa, Grandes Ecoles, Bizutage.

\section{SUMMARY}

The author analyzes the bizutage, a ritualized tradition of raggings that until recently characterized a particular sector of the French university system, that of the "prépas" and the "Grandes Ecoles". After presenting the defining traits and history of this education system, and interpreting the bizutage's symbolic and social components - space, time, actors, language, trials and punishments-, the author argues that the bizutage truly constituted a rite of initiation, with its three well defined parts: separation, margin and incorporation. The rite facilitated the social reproduction of a relationship of domination - that expressed in the degrees of the Grandes Ecoles - and the perpetuation of an elite. It also created a "distinction". The public debate about the recent prohibition of the bizutage reveals the extent to which the true nature of the Grandes Ecoles, i.e. their social elitism, is concealed. The selection rules at the Grandes Ecoles are presented as based upon the "natural" criteria of intellectual ability and individual effort.

Key words: Initiation rites, Raggings, Ritual, Social reproduction, French university system, Grandes Ecoles, Bizutage.

RDTP, LVIII, 2 (2003): 93-140 


\section{INTRODUCCIÓN}

Hasta fechas recientes, y a principios de cada curso, los estudiantes de enseñanza superior en Francia se entregaban al bizutage, práctica tradicional que consistía en una serie de novatadas y bromas, a veces bastante espectaculares, gastadas por los veteranos a los alumnos recién llegados. El término bizutage se refiere exclusivamente a esa clase particular de novatadas que tenía lugar en las instituciones del sistema de las "Grandes Ecoles", florón de la enseñanza superior en Francia.

Mucho más que una simple fiesta de inicio del curso, el bizutage presenta ciertas características reveladoras de su importancia social. Primero su extensión en el tiempo —de dos o tres semanas hasta dos meses de dedicación completa por parte de los estudiantes-y su repetición sistemática al empezar cada curso. Luego su carácter obligatorio y colectivo. También su estricta codificación según una tradición propia de cada institución, pero con una serie de rasgos comunes que daban al bizutage su unidad como fenómeno sociocultural. Finalmente, el carácter externo del ritual, que no se confinaba únicamente en el interior de cada institución sino que se desarrollaba en espacios públicos, manifestándose y comunicándose al resto de la sociedad. La cuestión de por qué existía un ritual de bizutage en ciertas escuelas y no en otras remite, como trataré de mostrar, a las relaciones particulares que vinculan estas instituciones con el conjunto del sistema de enseñanza y con las relaciones sociales que prevalecen en la sociedad francesa.

Las novatadas en general constituyen un fenómeno extendido que se puede observar en variadas organizaciones o instituciones de las sociedades occidentales, sea en el ámbito educativo, en el servicio militar, en ciertas corporaciones o sociedades profesionales, etc. Por muchas de sus características, recuerdan a los ritos de iniciación estudiados tradicionalmente por los antropólogos en las llamadas "sociedades primitivas". Las novatadas, la mili, las despedidas de soltero, son algunos ejemplos de la existencia de tales ritos de iniciación en las sociedades modernas. Por ello, resulta de gran interés el estudio de una manifestación de éstos en la vida social actual que se presenta no sólo como fuertemente ritualizada, producto de una larga tradición, sino además con rasgos iniciáticos muy patentes, como se desprenderá del presente análisis ${ }^{1}$. Y en tanto que rito de iniciación, al igual que en las

\footnotetext{
${ }^{1}$ Una primera versión del presente trabajo fue presentada bajo el título, "El bizutage: estudio antropológico de un ritual estudiantil francés", a la Primera convocatoria para trabajos de investigación de estudiantes de tercer ciclo de la Facultad de Ciencias Políticas y Sociología de la UCM, obteniendo el primer premio (febrero 2000).
} 
llamadas "sociedades primitivas", condensa muchos aspectos del funcionamiento de las instituciones en las que tiene lugar, y de las relaciones sociales más amplias en las que se inscribe. En efecto, el bizutage, fenómeno ligado a las instituciones de enseñanza superior más prestigiosas de Francia, presenta, a priori, un marcado contraste con la representación común de tales instituciones, destinadas en principio a la formación intelectual de alto nivel, eficaz, racional y ordenada, de los futuros cadres de la nation (responsables de la nación); formación basada en las capacidades, en el mérito y en el esfuerzo individuales. Son los "mejores" alumnos del sistema educativo, aquellos que son destinados a formar la elite intelectual del país, quienes se entregan a una serie de prácticas que, para muchos, asombran por su "estupidez", y que varias voces de la sociedad califican hoy de "bárbaras", "salvajes", "humillantes" y "degradantes", tras años de aceptación tácita y de tolerancia general. Pero como escribe J. Zulaika en su estudio de la mili como ritual de iniciación, "[...] la labor del antropólogo parece guiarse [...] por la premisa de que cuanto más extraña e inexplicable es una costumbre o institución, más deslumbrantes son las lecciones que se desprenden de la misma" (Zulaika 1989: 12).

Una ley que prohibe la práctica del bizutage fue aprobada recientemente tras una amplia polémica ${ }^{2}$. El curso 99/2000 fue el primero en el que oficialmente el bizutage ya no se llevó a cabo o, en todo caso, en el que fue amenazado de represión severa. Tales acontecimientos - la controversia pública y el cambio legislativo- despertaron mi interés por comprender mejor un fenómeno que me resultaba familiar, como ciudadana francesa y antigua alumna del sistema francés de educación superior.

En el marco de la polémica que suscitó la prohibición legal del bizutage, el sociólogo francés René Devos intentó ofrecer una explicación del fenómeno que, sin embargo, no me parece satisfactoria. Según él, la escuela es una "máquina de distribución de saber, que se muestra incapaz de integrar a sus alumnos en un amplio proyecto de sociedad"; por lo que, en lo que "ya no es más que un desierto, y sea cual sea el nombre que se le da, el bizutage es el punto de anclaje del pensamiento totalitario" (Devos 1998). Creo que se debe ir más allá de afirmar simplemente el carácter "totalitario" del bizutage, si se quiere entender profundamente su naturaleza. Además, el hecho de verlo como mero instrumento de integración social, que suple

\footnotetext{
${ }^{2}$ Desde el 20 de enero de 1998, se ha instaurado la posibilidad de entablar diligencias judiciales, incluso sin que haya una denuncia previa, contra comportamientos calificados de "perjudiciales a la dignidad de la persona humana" en el marco del bizutage, y la represión prevista es severa.

${ }^{3}$ El título de su artículo en Libération del 1/10/98 se puede traducir por "El bizutage es totalitario".
} 
el papel que normalmente le corresponde a la escuela, y que ésta ya no puede cumplir, me parece que deja de lado aspectos importantes de la cuestión. En efecto, significa no ver que es justamente en las instituciones de enseñanza que mejor consiguen la integración de sus estudiantes en "un amplio proyecto de sociedad" - es decir aquellas que mejor garantizan un futuro éxito social y económico- donde el bizutage se ha desarrollado principalmente. El bizutage no es de ningún modo un fenómeno reciente que hubiera aparecido con una crisis de la escuela, como sugiere R. Devos. Su análisis tampoco permite entender lo que está en juego en el debate que opone a los defensores del bizutage (instituciones donde se ha practicado tradicionalmente, asociaciones de antiguos alumnos) y a los que luchan por prohibirlo y reprimirlo. Hay más que una simple cuestión de integración social de los recién llegados. Si se limitara a eso, ipor qué entonces sería necesario pasar varias semanas dedicándose a actividades que se perciben como inútiles y absurdas, y tratar de someter a los recién llegados a la autoridad de los veteranos? Hay también más que una supuesta oposición entre pensamiento totalitario y pensamiento democrático. Como intentaré mostrar, los rasgos del bizutage que se pueden calificar de "totalitarios" parecen más bien producidos y mantenidos por las normas y los valores de las mismas instituciones educativas en las que se practicaba el ritual.

$\mathrm{Al}$ igual que la violencia doméstica, hasta que empezara recientemente a hacerse más visible, y que se volviera "políticamente correcto" el denunciarla y condenarla, el bizutage constituyó durante mucho tiempo una práctica perfectamente admitida, que resultaba divertida, y de la cual casi nadie percibía el carácter "humillante", "degradante" o "bárbaro". Los abusos, las violencias y otros desbordamientos que, a veces, se producían, eran vistos como simples accidentes, como efectos secundarios no deseados e inevitables de una tradición que formaba parte intrínseca del sistema francés de enseñanza superior.

¿Cuáles son las características del bizutage? ¿Qué funciones cumple? ¿Qué es lo que ocurre durante un bizutage? ¿Qué es lo que nos dice sobre el sistema de enseñanza en Francia y sobre la sociedad en general? Basándome en mi propia experiencia del ritual, del que personalmente fui "víctima" en 1976, y en una serie de entrevistas a antiguos "bizuts" y veteranos ${ }^{4}$, quiero

${ }^{4}$ El material etnográfico analizado aquí procede, pues, de dos fuentes. En primer lugar de unas 15 entrevistas realizadas durante la primavera del 1999, a hombres y mujeres franceses que proceden de distintas ramas de la enseñanza superior (empresariales, ingenieros, agrónomos, médicos, etc.) y fueron elegidos variando la época en que experimentaron el bizutage (desde 1948 hasta 1996). En su mayoría, los informantes no sólo habían sido iniciados sino que también habían participado, en tanto que veteranos, en la iniciación de los nuevos alumnos. Por otra parte, de mis recuerdos 
describir y analizar el bizutage, mostrando en qué medida constituye un verdadero ritual de iniciación; cuáles son los significados sociales y culturales que se manipulan durante su desarrollo, y cómo éstos se pueden entender en el marco de un conjunto de relaciones en la sociedad francesa que se cristalizan y se reproducen —en parte- a través de su sistema de enseñanza superior.

\section{BIZUTAGE Y ENSEÑANZA SUPERIOR}

\section{El bizutage: significado e importancia}

El bizutage constituye un conjunto ritual tradicional, organizado (o mejor dicho "reactivado") por los propios estudiantes a principios de cada curso, en el que los veteranos gastan una serie de bromas y novatadas a menudo bastante duras, incluso crueles, a los alumnos novatos ${ }^{5}$. El ritual del bizutage tiene una duración de entre dos y cuatro semanas, y a veces más: dos meses, por ejemplo, en la Escuela Nacional de Artes y Oficios, institución de formación de ingenieros. No concierne a todas las instituciones de enseñanza superior, sino sólo a un conjunto bien específico: las clases preparatorias a las "Grandes Ecoles" que se cursan después de la Selectividad (el Baccalauréat), algunas escuelas superiores, y las Facultades de Medicina. Se desarrolla siempre a principios del curso, perturbando total o parcialmente la vida escolar. Durante todo el bizutage, los veteranos dirigen a los bizuts, los recién llegados, quienes deben ejecutar todas sus órdenes, sea dentro de la institución, sea fuera de ella, en la calle u otros lugares públicos. Las distintas actividades, que se desmarcan nítidamente de la escolaridad normal, pueden ser colectivas o individuales, pero en este último caso el grupo de bizuts está siempre bajo el control y la autoridad de los veteranos, mientras los alumnos sufren las pruebas por turno. El final del bizutage viene marcado por una fiesta con comida y bebida. Al día siguiente, las clases empiezan de nuevo y la institución parece "cambiar de mando": la administración y los profesores vuelven a tomar el control, es la vuelta al orden.

Se trata de un fenómeno tan extendido y regular que uno puede fácilmente darse cuenta de que ha llegado la época del bizutage a las calles de París; sobre todo a los barrios de estudiantes, como el Quartier Latin: grupos

personales del bizutage que sufrí como inicianda cuando cursé la clase preparatoria (rama de ciencias empresariales) en un instituto parisino, al iniciar el curso 1975/1976, y de las observaciones que hice y de los relatos que recogí durante mis años como estudiante en la enseñanza superior francesa (de 1975 a 1980).

5 Utilizo el "presente etnográfico" para describir los rasgos generales que caracterizaban el bizutage mientras seguía siendo una práctica vigente (hasta el curso 1998/99). 
estudiantiles fácilmente identificables se dedican a toda clase de tonterías y ruidos. El clima general del bizutage es de broma, de cachondeo, de burla, y así lo entiende el público en general, que asiste divertido a las exhibiciones exuberantes de los estudiantes, como también los padres y otros estudiantes. En este sentido tiene una dimensión carnavalesca, de fiesta y permisividad, que contrasta con la seriedad y la dureza de los estudios que se cursan. En las clases preparatorias se exige un trabajo muy intenso para hacer frente a las oposiciones sumamente selectivas de ingreso en las Grandes Ecoles, las Escuelas Superiores.

Si bien parece constituir una broma extendida, el bizutage no deja de ser un asunto muy serio, por su carácter sistemático y obligatorio y por la importancia de los recursos movilizados. Las pruebas del bizutage comportan cierto grado de violencia sobre los bizuts y hasta se les imponen castigos físicos en caso de rebelión, si bien en general hay un consenso por aceptar finalmente las pruebas y los castigos como parte de una tradición divertida.

Procediendo a una breve incursión lingüística, se descubre que al novato que sufre el ritual se le llama "bizut", palabra que da su nombre a aquél (bizutage) así como a términos derivados, como el verbo "bizuter" o "être bizuté". Hay una cierta circularidad en este análisis lingüístico - los bizuts son aquellos que sufren el bizutage, nombre que a su vez deriva de la palabra bizut -, de la que resulta imposible salir, debido al desconocimiento del origen del vocablo bizutage, según el diccionario histórico Robert. Si bien se han propuesto muchas interpretaciones, ninguna parece satisfactoria. El uso del vocablo se documenta ya en 1843 , en la escuela militar Saint-Cyr. No se trata, pues, de un producto reciente del argot. Los veteranos, en cambio, tienen nombres distintos según la rama de estudios a la que pertenecen: como "Trois demis" o "Cinq demis" ("Tres medios" o "Cinco medios") para los veteranos de preparación a las escuelas de ingenieros, o "Carré" (cuadrado) para los de la rama de ciencias empresariales. El bizut, sin embargo, es lo constante.

Estos datos lingüísticos nos muestran que, históricamente, se ha cristalizado una tradición, un fenómeno sociocultural particular, que todos los franceses entienden e identifican claramente, asociándolo a las clases preparatorias y a las Grandes Ecoles. Por ello se revela útil relacionar la práctica del ritual y sus contenidos específicos con el sistema francés de enseñanza superior y el papel particular de las Grandes Ecoles en la sociedad y cultura de Francia.

\section{Las "Grandes Ecoles"}

El rasgo más destacable del sistema de enseñanza superior en ese país es, sin duda, la distinción entre las universidades y las "Grandes Ecoles" (Es- 
cuelas superiores). Las universidades son públicas y aceptan alumnos con el Baccalauréat (equivalente a la Selectividad), título que marca el final de la enseñanza secundaria y sirve al mismo tiempo como prueba de entrada a los estudios superiores. Casi no hay selección para la entrada en la universidad. Los criterios son más bien regionales; normalmente se estudia en la academia de residencia. El número de estudiantes en la universidad es muy alto, sobre todo en los primeros cursos. En cambio, el sistema de Grandes Ecoles es muy selectivo desde el principio: cada escuela limita el número de alumnos admitidos por medio de unas oposiciones, y por otra parte no se puede acceder a una Grande Ecole sin pasar por el sistema de "clases preparatorias", después del Baccalauréat, clases que se suelen cursar en grandes institutos públicos o privados (los lycées) y que constituyen una enseñanza muy distinta y separada de la secundaria, a pesar de tener lugar en los mismos centros. El nivel del profesorado es más alto y el ritmo mucho más intenso, con el fin de preparar a los alumnos a las oposiciones de ingreso en las escuelas. La reputación de un instituto, en cuanto a sus clases preparatorias, se mide en función de las tasas de admisión anuales en las distintas escuelas, teniendo en cuenta la clasificación de éstas últimas según su prestigio; prestigio que se traduce normalmente por la dificultad mayor o menor de las oposiciones para entrar. La duración del ciclo preparatorio es, en general, de dos años, y se vuelve a hacer un año más, o incluso dos, en caso de fracaso en las oposiciones. Las clases preparatorias se dividen en ramas, según la categoría de las oposiciones preparadas, con un contenido adaptado a cada caso.

De forma general, las Grandes Ecoles gozan de una reputación mucho mayor que las universidades si unas y otras se comparan en ramas equivalentes. Pero no hay superposición exacta de los dos sistemas, puesto que esas escuelas tienen una orientación más práctica y aplicada que la universidad y pretenden preparar para las carreras en las empresas privadas o públicas del país. Las de mayor reputación se originan históricamente en los esfuerzos de Napoléon I por formar una elite de "cadres" (ejecutivos), con el fin de aplicar los conocimientos científicos al desarrollo de la potencia militar y civil del país. Podemos nombrar las principales:

- l'Ecole Polytechnique: ingenieros generales; la escuela tiene lazos estrechos con el Ministerio de Defensa y sus alumnos son al mismo tiempo oficiales del ejército;

- Saint-Cyr (escuela militar);

- l'Ecole Normale Supérieure (con dos ramas: ciencias y letras);

- l'Agro: ingenieros de agronomía;

- les Beaux-Arts: bellas artes; 
- l'Ecole Nationale des Arts et Métiers (artes y oficios): ingenieros de producción;

- l'Ecole Supérieure des Télécommunications: ingenieros de telecomunicaciones;

- l'Ecole des Mines: ingenieros de minas;

- l'Ecole des Ponts et Chaussées: ingenieros de caminos;

- l'Ecole des Hautes Etudes Commerciales: ciencias empresariales;

- I'ESSEC: ciencias empresariales.

Para entender los valores subyacentes a estas instituciones y los principios educativos que las caracterizan, resulta útil evocar el proceso histórico en el que fueron creadas. En efecto, como señalé más arriba, la mayoría de las instituciones en las que se ha practicado tradicionalmente el bizutage nació a finales del siglo XVIII o principios del siglo XIX, después de la Revolución Francesa, y en particular bajo Napoléon Bonaparte (Mason 1986: 59-76). Tras el periodo jacobino se produce una rápida reconstitución por la Convención Nacional, en 1794, de las instituciones científicas bajo nuevas formas, así como la creación de nuevas instituciones, con el fin de resolver los problemas técnicos de la época. El objetivo era formar nuevos científicos, acogiendo a personas que no eran miembros de la nobleza en las instituciones. Pero al mismo tiempo se produjo un cambio en la concepción de la ciencia y del trabajo de los científicos, que se volvió mucho más aplicada, orientada hacia los problemas militares y civiles del país. Así nacieron el Instituto de Francia (transformación de la antigua Academia de Ciencias), el Conservatorio de Artes y Oficios (escuela y museo a la vez, que alcanzó luego la reputación de "Sorbona industrial"), la Escuela Politécnica (cuna de los mejores físicos y matemáticos), la Escuela Normal Superior, y diversas escuelas militares y médicas. Napoléon prosiguió este impulso, fundando otras varias escuelas para promover los aspectos aplicados de la ciencia en los campos militar e industrial. Al mismo tiempo cerró en 1803 las secciones de ciencias morales y políticas del Instituto de Francia, desanimando a los pensadores especulativos y la continuación de la tradición filosófica del siglo anterior.

Aquellas instituciones florecieron a lo largo del siglo XIX, y hasta hoy representan las más prestigiosas de la enseñanza superior, formando a los mejores científicos en ciencia aplicada, que se destinan a ocupar puestos de dirección en la industria y el ejército del país. Muchas nuevas escuelas se desarrollaron más tarde, a finales del siglo XIX y principios del XX —n particular las escuelas de ciencias empresariales-, pero todas resultan del mismo movimiento, de la misma concepción.

Las Grandes Ecoles se caracterizan por un doble principio fuertemente marcado, de competición y de elitismo; rasgos estrechamente ligados entre 
sí y que se apoyan mutuamente. Para la selección, cada Grande Ecole organiza unas oposiciones de ingreso muy competitivas, de alto nivel intelectual, compuestas de 4 ó 5 días de pruebas escritas, seguidos de otros 4 ó 5 días de pruebas orales, a las que se presentan cada año varios miles de candidatos procedentes de las clases preparatorias. La eliminación es fuerte, ya que sólo entre 200 y 400 estudiantes resultarán admitidos en cada escuela. La competición ocurre después de una selección previa, realizada en el momento del ingreso en las clases preparatorias: a ellas accede sólo una pequeña parte de los alumnos que han aprobado la selectividad (Baccalauréat). La rigurosa selección se basa en los resultados del Baccalauréat y en las notas de los últimos tres años de secundaria. Los estudiantes que luego son eliminados de las clases preparatorias, porque no han aprobado ninguna de las oposiciones, tienen que volver a empezar la universidad, sin haber obtenido ningún título. Tras las oposiciones, y una vez admitido en una Grande Ecole, el estudiante cursa un ciclo que dura tres años en general y acaba con la obtención del título de la escuela. Es importante apuntar que lo esencial de la selección se realiza antes de cursar las Grandes Ecoles, ya que una vez obtenido el ingreso, hay muy pocos estudiantes que no acaben consiguiendo el título. Algunas instituciones siguen con un sistema competitivo durante los estudios, que permite la atribución de un rango de salida, pero en todo caso esa competición es mucho menos marcada que en las oposiciones de ingreso.

El elitismo se traduce por la reputación que tiene cada escuela y que le permite ubicarse en una escala de prestigio dentro del conjunto de instituciones. En función de esta posición, las pruebas se hacen más o menos difíciles para, justamente, seleccionar la elite de estudiantes que corresponde a su reputación. Se trata de un elitismo que se presenta como intelectual - siendo por supuesto también social - y no directamente económico, en la medida en que las mejores escuelas no son las más caras (al contrario: la Ecole Polytechnique, número uno de las escuelas científicas, es gratuita y

\footnotetext{
${ }^{6}$ El elitismo social es sin embargo un rasgo no reconocido, pues esas escuelas pretenden reclutar los mejores cerebros independientemente de su procedencia social. En realidad, muchos mecanismos actúan, a nivel del entorno familiar, del sistema de enseñanza primaria y secundaria, y de las instituciones sociales en general para hacer más probable el acceso a las Grandes Ecoles de hijos de las clases con "capital cultural, social y económico" alto, según el concepto de "capital" desarrollado por Bourdieu (1979). En su libro Los estudiantes y la cultura, coescrito con Jean Claude Passeron (1966), Bourdieu subraya "la diferente situación que los estudiantes, según su origen social, establecen con la cultura académica" y cómo "estas diferencias se traducen en aptitudes distintas para llegar al término del cursus escolar". Véase la introducción de La Reproducción, Bourdieu y Passeron (1977: 11).
} 
además los estudiantes cobran un salario durante la carrera, en tanto que oficiales del ejército), gracias a unos sistemas de becas estatales o propios de cada institución. El proceso usual para los alumnos de clases preparatorias consiste en presentarse a las oposiciones más duras, las de las mejores escuelas y, en caso de fracaso, preparar las de las escuelas de segundo rango.

En comparación, el sistema universitario es mucho menos competitivo y selectivo: admite en teoría a todos los estudiantes que lo deseen, con la condición de haber aprobado el Baccalauréat. Hay, por supuesto, una selección socioeconómica de hecho (preparación intelectual, actitud ante la cultura y los estudios, y posibilidad económica para estudiar varios años), pero que actúa en gran medida antes de llegar a la universidad (Bourdieu y Passeron 1977; Bourdieu 1979). Así, a principios de los años 80, sólo un $6 \%$ de los estudiantes universitarios procedía de un medio familiar obrero, mientras que las clases medias y altas estaban sobrerrepresentadas, no obstante el carácter gratuito de la universidad.

Una excepción notable la representa la enseñanza de medicina. Se cursa en facultades específicas que, a pesar de su pertenencia a la universidad, manifiestan características más típicas de las Grandes Ecoles que de aquélla. La selección en medicina es drástica: el estudiante tiene un máximo de tres años para aprobar los dos primeros cursos del ciclo. Si no aprueba dentro de ese plazo, no puede seguir en la carrera y tiene que salir del sistema. El nivel de enseñanza es también muy alto, exigiendo un trabajo intelectual intenso, lo que tiene como resultado una tasa elevada de eliminación.

El valor de los títulos de las Grandes Ecoles y de medicina es mucho mayor que el de los títulos universitarios. Aquellas instituciones le aseguran de manera casi automática al titulado el ingreso en el mundo profesional como ejecutivo o ingeniero (o médico) principiante; es decir, en el nivel más alto en que se puede empezar una carrera profesional. Varios factores actúan para ello. En primer lugar, los criterios de selección de las empresas y administraciones privilegian a los candidatos con títulos de Grandes Ecoles de manera sistemática en comparación con los universitarios. Además, se apoyan en una clasificación de reputación actualizada cada año en función de la opinión de los actores económicos del país, determinando el rango de cada título. En realidad, los rangos varían muy poco con el tiempo. Por otra parte, las propias escuelas dedican muchos esfuerzos a la consecución de puestos interesantes para sus titulados. Desarrollan encuentros con las empresas, contactos permanentes; "venden" enérgicamente la calidad de los estudios y el nivel de sus estudiantes. El interés de una institución de primer rango es tener una red de antiguos alumnos situados en las mayores empresas, con puestos de alto nivel. En cambio, la universidad desarrolla muy pocas relaciones con 
el mundo empresarial y se desinteresa, de hecho, de la carrera de sus titulados.

Finalmente, existe también un fuerte corporativismo de los titulados, que se expresa en las asociaciones de antiguos alumnos. Aquellas organizaciones, basadas en la solidaridad de los graduados de una misma escuela superior, tienen un peso importante y pueden ayudar a sus miembros en su carrera profesional. En primer lugar, proporcionan informaciones esenciales para facilitar la búsqueda de los mejores puestos de trabajo y los necesarios contactos profesionales (como ofertas de trabajo o listados de antiguos alumnos con su puesto actual). Por otra parte, mantienen viva la solidaridad de los miembros y el vínculo con su institución de origen mediante manifestaciones, fiestas, encuentros. A pesar de una diferencia de edad o de situación profesional marcada, e incluso sin conocerse, los titulados de la misma escuela suelen tutearse ${ }^{7}$. La solidaridad borra las demás diferencias y obliga a una actitud de ayuda mutua, percibida como beneficiosa para todos. En 1974, cuando estaba en plena campaña electoral para la presidencia del país, Valéry Giscardd'Estaing escribió una carta a cada uno de los antiguos alumnos de l'Ecole Polytechnique - la más prestigiosa de las escuelas de ingenieros, y en la que se había formado- tuteándolo y llamándolo "cher camarade". La solidaridad entre antiguos alumnos no se podía desdeñar en la caza de votos. El corporativismo se manifiesta, de hecho, por la existencia de "mafias" de tal o cual escuela en las grandes empresas del país. Los dirigentes tienden a favorecer la contratación de titulados de su propia escuela, y luego a facilitar la carrera interna de los mismos, lo que acaba constituyendo un cuerpo de ejecutivos de dirección con el mismo título.

La mejor prueba del valor asociado a los títulos y de la importancia del sistema de Grandes Ecoles lo proporciona la fuerte representación de los titulados por este sistema en la clase dirigente del país; es decir en los puestos de directores y ejecutivos de empresas y administraciones. Sin embargo, el sistema de Grandes Ecoles no conduce específicamente a las carreras políticas y sus titulados no están muy presentes en ellas. La carrera política se gestiona generalmente mediante unas vías de formación distintas. La mejor vía, la más prestigiosa, pasa por la ENA (Ecole Nationale d'Administration). Esta escuela superior fue creada en 1945 por Charles de Gaulle para formar a los futuros altos funcionarios del Estado, con el fin de romper con los funcionarios del régimen de Vichy y constituir una nueva élite política. Existe también otro camino para acceder a los puestos políticos: la militancia y el desarrollo de una carrera dentro de las organizaciones políticas, como los

\footnotetext{
7 El tuteo es, por otra parte, mucho menos utilizado en Francia que en España, y reservado para las relaciones con familiares y amigos.
} 
partidos o los sindicatos. Tenemos entonces una cierta separación entre el sistema que proporciona los responsables políticos del país y el que forma a la elite económica, aunque existan superposiciones y puentes entre ambos.

\section{Enseñanza superior y género}

El sistema de Grandes Ecoles y la universidad se diferencian también por otro rasgo sociológico: la tasa de representación femenina. Es importante subrayar que, hasta hace poco (la década de 1970), en su mayoría las Grandes Ecoles eran exclusivamente masculinas. La presencia de mujeres sigue siendo muy limitada en las escuelas de ingenieros, sobre todo en las más prestigiosas. La Ecole Polytechnique, por ejemplo, tiene una proporción de mujeres muy baja $\left(10\right.$ a $\left.12 \%{ }^{8}\right)$ a pesar de su aumento regular desde los años 70. Además, probablemente su lazo con el ejército actúa desanimando la entrada de mujeres. En las ramas de preparación a las escuelas de ciencias empresariales, y en las escuelas correspondientes, la proporción femenina es más alta (un 30\%), pero sigue muy por debajo de la media de la universidad, donde alcanza más del $50 \%$.

Tras el paulatino acceso de las mujeres a muchas instancias de la sociedad que las había mantenido excluidas, en particular tras el movimiento de mayo de 1968, se puede observar, al mismo tiempo, una distribución entre carreras "femeninas" y carreras que siguen percibiéndose como "masculinas". Las Grandes Ecoles pertenecen más bien a la segunda categoría, pues su imagen va asociada con el prestigio y el poder, mucho más que en la universidad. En el ámbito de las ciencias empresariales, aunque la representación femenina es más importante, se puede, sin embargo, observar una distribución bastante nítida de las especialidades y de las carreras profesionales elegidas según el género: las finanzas y la estrategia son carreras típicamente masculinas, mientras que en el marketing, la publicidad o la venta hay cada vez más mujeres. Así, pues, se pueden observar las "permanencias en el cambio" que describe Bourdieu (1998: 89-115) cuando analiza la reproducción de las estructuras diferenciadoras que permiten perpetuar una relación de dominación entre los géneros, a pesar de la influencia de unos factores de cambio que han transformado drásticamente la condición de las mujeres, en particular el acceso masivo de estas últimas a la enseñanza secundaria y superior. Bourdieu destaca tres principios que, según él, siguen rigiendo la elección de los estudios y carreras profesionales por parte de las mujeres y de su entorno familiar y social. El primer principio es la orienta-

${ }^{8}$ El $12 \%$ de los titulados en 1998 fueron mujeres, así como el $15 \%$ de los admitidos en las oposiciones de ingreso en 2002. 
ción hacia las funciones sociales que prolongan las funciones domésticas tradicionales de la mujer; es decir la enseñanza, el cuidado y el servicio. Según el segundo principio, una mujer no puede tener autoridad sobre hombres: con mucha probabilidad, y en condiciones similares, un hombre será elegido preferentemente para una posición de autoridad. Finalmente, según el tercer principio, el hombre sigue teniendo el monopolio de la manipulación de los objetos técnicos y de las máquinas. Estos principios son "incorporados" por las mujeres bajo la forma de "esquemas de percepción y de apreciación difícilmente asequibles a la conciencia, que les lleva a percibir como normal, o incluso natural, el orden social tal como es, y a anticiparse en cierta forma a su destino, rechazando las carreras que las excluyen y eligiendo aquellas a las que están destinadas" (Bourdieu 1998: 102)9.

Así, a pesar de haber franqueado la frontera que hacía del sistema de Grandes Ecoles un lugar exclusivamente masculino, al ser la mejor vía de acceso a los puestos de poder en la economía, se sigue perpetuando una especialización por género que acaba relegando sistemáticamente a las mujeres a posiciones que, si bien son mucho mejores que hace apenas treinta años, no dejan de ser subalternas. En medicina, se aplica la misma observación: muchas mujeres han entrado en la carrera médica, pero las especialidades más prestigiosas (cirugía, por ejemplo) y los puestos de mando (director de hospital, jefe de servicio clínico) no se han feminizado, mientras la pediatría, la ginecología (pero no la obstetricia) y la dermatología, sea por su proximidad a las actividades "naturalmente" femeninas o por su menor prestigio profesional, son especialidades con una representación femenina importante ${ }^{10}$.

\section{Historia del bizutage}

En cuanto a la historia del bizutage, cabe considerar, pese a la ausencia de datos, que el ritual es tan antiguo como la reputación de las instituciones en las que ha tenido lugar. En todo caso, no es un fenómeno reciente. Sobre todo, la (limitada) información histórica que se puede recoger entre los testigos de más edad muestra la extraordinaria estabilidad del fenómeno en

\footnotetext{
9 Traducción mía.

${ }^{10}$ Howard Becker describe los valores en los que se forman los estudiantes americanos en medicina, en su libro Tricks of the Trade, subrayando la centralidad de la noción de "responsabilidad médica", según la cual, extrañamente para las personas legas, uno está plenamente actuando como médico sólo cuando lo que hace podría matar al paciente, en caso de error. A partir de aquella concepción, la especialidad de dermatología se encuentra despreciada de forma sistemática, pues en ella "no puedes matar a nadie y no puedes curar a nadie" (1998: 157). Traducción mía.
} 
cuanto a las instituciones que lo han practicado, fundando la práctica en una tradición antigua, que se ha mantenido en el tiempo, a pesar de otros cambios a veces muy importantes en la vida de la institución; como por ejemplo la apertura a las mujeres, el desplazamiento físico de una escuela a nuevos recintos modernos fuera del centro estudiantil de la ciudad, o la modernización de los programas y de los métodos de enseñanza. Por el contrario, en instituciones donde no se ha practicado el bizutage, parece que nunca se dio.

Por otro lado, no era un fenómeno en vía de desaparición, hasta su reciente prohibición. En un artículo de Le Monde sobre el proyecto de ley de prohibición y el debate consiguiente, se afirmaba más bien lo contrario: después de una ligera bajada en la práctica del bizutage durante los años 80, se asistió a un recrudecimiento en la década de 1990. Al parecer, mientras la voz de los oponentes al ritual se hacía más fuerte, rompiendo la "ley de silencio" y el consenso general del que se beneficiaba la costumbre, ésta se afirmaba con más virulencia.

\section{EL RITUAL}

A pesar de la variedad de formas que podían tomar los bizutages, cada uno siguiendo la tradición propia de la institución en la que se desarrollaba, existían elementos y estructuras comunes que caracterizaban al ritual. Voy a destacar estas estructuras describiendo, en el presente, varias manifestaciones concretas, que se traducen en gestos, palabras, actos y objetos en un tiempo y en un espacio concretos, y con una determinada serie de actores sociales colectivamente implicados.

\section{El tiempo del bizutage}

Por lo general, el principio y el final del bizutage constituyen fases bien delimitadas, fácilmente identificables. El comienzo es una verdadera inauguración formal, que permite plantear las condiciones características del ritual, empezando por una ruptura temporal con la vida escolar normal. La fiesta organizada para terminar sirve, a la inversa, para marcar la vuelta al tiempo ordinario de la vida de los estudiantes, regido por la institución educativa y sus exigencias. Entre estos dos tiempos se desarrollan una serie de actividades que alternan entre lo colectivamente y lo individualmente sufrido, y entre el interior y el exterior de la escuela. Durante este tiempo especial, que dura varias semanas, los veteranos, que actúan como oficiantes del bizutage, ostentan el poder. La institución les pertenece, ya que son ellos los que deciden sobre la ocupación del tiempo y del espacio, y no dejan a los profeso- 
res ni a la administración llevar a cabo las actividades normales de docencia. Según los casos, esta toma de control sobre la función educativa puede ser total o sólo parcial, dejando momentos diarios o semanales en los que las clases sí tienen lugar.

El bizutage suele empezar el primer día del curso, en cuanto se encuentran reunidos los nuevos alumnos que no se conocen, por proceder de instituciones distintas o de ciudades diferentes. Rápidamente, los veteranos se apropian colectivamente del espacio reservado para la prépa (clase preparatoria): irrumpen sin avisar en las aulas de los nuevos alumnos y empiezan a dirigir las operaciones. Los profesores y miembros de la administración se retiran discretamente y no vuelven a aparecer hasta el final del bizutage. La primera cosa que suelen hacer los veteranos es convocar a una asamblea, en el patio por ejemplo, en la que todos los bizuts estén agrupados, esperando algún tipo de información. Sin embargo, los veteranos no explican el bizutage. Los nuevos no saben en qué consiste, cuánto tiempo va a durar, ni cómo se va a desarrollar, lo que permite a los veteranos imponer un carácter completamente arbitrario a la situación. En muchos casos, tras haber agrupado a los novatos en el patio, los veteranos se esconden en las aulas y pasillos de las plantas altas e inician una batalla general, tirando bombas de agua, paquetes de harina, huevos, yogures, etc. Se produce entonces cierta reacción por parte de los bizuts, que intentan responder colectivamente, tirando a su vez bombas de agua y todo lo que pueden recuperar. Sin embargo, la disposición espacial es totalmente desigual. Un grupo de bizuts intenta forzar el acceso a las aulas de arriba, pero los veteranos oponen una defensa bien organizada y el paso por las escaleras se hace imposible. Después de hora y media o dos horas de batalla general, las puertas del instituto finalmente se abren y los bizuts recuperan sus cosas en la medida en que los carrés (veteranos) no se lo impidan, pues a menudo se les roba las carteras, en particular a aquellos que han sido más rebeldes durante el "combate" inaugural. Los estudiantes se van después a comer, mojados y cubiertos de una mezcla de harina, yogur y huevo.

En ciertos institutos, la asamblea de inicio del bizutage se llama monôme, lo que conlleva una idea de tratamiento colectivo de los bizuts, en tanto que unidad. El monôme se contrapone al binôme, que designa a un par de dos alumnos que van a sufrir juntos las pruebas en las fases ulteriores del ritual. En esta primera asamblea se distribuyen boinas de color azul marino, que los bizuts deben llevar durante toda la duración del bizutage, con el nombre de la prépa y una insignia. También se roban los objetos personales de algunos bizuts, como en el caso previo.

Cabe señalar que en muchas prépas y escuelas existe un internado. Si bien se da una nítida separación entre la vida escolar diurna y la vida del 
internado, el bizutage franquea esa frontera: los veteranos internos organizan todo tipo de novatadas dentro del internado, lo que empieza también con algún tipo de ceremonia inaugural: como, por ejemplo, irrumpir masivamente en los cuartos de los nuevos, sacar a todos vestidos en pijama al patio y quitarles sus objetos personales.

El final del bizutage consiste en una gran fiesta que reúne a todos los veteranos y a los bizuts. Se pide antes una participación económica individual, a la que se añade el dinero recaudado durante el bizutage, para comprar bebida y comida. En ciertos casos, se procede a una última ceremonia para inaugurar la fiesta. Ésta puede consistir, por ejemplo, en agrupar a todos los bizuts en un aula grande, donde sufren colectivamente varias novatadas más. Luego cada bizut tiene que pasar a otra aula pequeña, con los ojos tapados. Los veteranos le dan varias vueltas, le hacen sentarse en una silla y le obligan por la fuerza a comer un plátano untado de mostaza ${ }^{11}$. Tras esta última prueba, el bizutage del novato se considera terminado: puede unirse al grupo para la fiesta. El día de clase que sigue a la fiesta marca el retorno al orden, a la actividad normal, al trabajo escolar intenso. Los profesores imparten sus clases y exigen silencio, orden y trabajo, en contraste con el clima de las semanas anteriores.

\section{El espacio del bizutage}

Los veteranos, que se han apropiado del espacio interno de la institución para llevar a cabo el conjunto ritual, organizan dos tipos de actividades que se desarrollan en alternancia: actividades individuales, o en binôme, y actividades colectivas. También es muy importante llevar el bizutage fuera de los límites de la institución, a un espacio público, que puede ser la calle, los parques de la ciudad o el metro. Para ello, se realizan toda una serie de actividades específicas que tienden a ser lo más visibles y ruidosas posible.

El espacio interno es el típico espacio educativo: aulas, pasillos y patios. La manera de utilizarlo constituye a menudo una parodia de las actividades educativas. Por ejemplo, en las aulas se organizan "exámenes" individuales, que sufren los bizuts por turno, individualmente o de dos en dos (en binôme), frente a un "tribunal" compuesto de tres o cuatro veteranos. Esta parodia de examen suele llevar un nombre que recuerda el examen oral individual o en binôme típico de las clases preparatorias. En la rama de preparación a las escuelas de ingenieros, la prueba usual del bizutage se llama "kholle" en referencia a la "colle" que es el término para los exámenes orales en la jer-

11 La mostaza francesa suele ser muy fuerte: el ingerir una cucharada provoca el efecto de quemar la boca y la garganta, hacer llorar y estornudar. 
ga estudiantil. La colle, caracterizada por su dificultad, no sólo intelectual sino también psicológica, representa la mayor fuente de temor de los estudiantes ("coller" significa "pillar en bragas"). En esas pruebas, organizadas regularmente durante todo el curso, los profesores, además de verificar los conocimientos adquiridos, suelen probar la capacidad de autocontrol y de autoafirmación de los alumnos, y su talento para devolver la pelota, imponiendo todo tipo de trampas y humillaciones; y todo ello con el fin de preparar a los candidatos para las pruebas orales de ingreso en las Grandes Ecoles. En el bizutage, mientras la parodia de prueba tiene lugar, el resto de los novatos se queda fuera de las aulas bajo el mando de los demás veteranos que aseguran, con cierta brutalidad física, el paso por turno de todos los nuevos. El negarse a sufrir la prueba se reprime duramente: tres o cuatro veteranos cogen al bizut recalcitrante y lo llevan a rastras al aula; además le imponen determinados castigos por su rebelión. Ello provoca nuevas batallas o riñas que estallan en los pasillos.

El patio es el lugar de las asambleas generales, que imitan también una práctica corriente del sistema educativo, utilizada por la administración para transmitir informaciones que conciernen a un conjunto numeroso de alumnos. Pero, en el bizutage, el objetivo de información se transforma en pelea general, como en la inauguración antes descrita y, del mismo modo que durante una verdadera guerra, es el control de los espacios estratégicos lo que demuestra la posición de poder. El control espacial por los veteranos se extiende también a los comedores y a la zona de internado. Durante las comidas del mediodía, se enfrentan colectivamente a los bizuts organizando combates con pan y agua; en los internados, no existe espacio de refugio para un bizut, sea su cuarto, las duchas o las salas comunes: todos estos lugares pueden ser sitiados por los veteranos de manera imprevista y a cualquier hora.

No existe escapatoria a las reglas colectivas impuestas por los veteranos en el espacio de la institución. Resulta imposible salir del instituto antes del final del día: las ausencias son severamente reprimidas. La única solución es, entonces, desaparecer durante toda la duración del ritual; pero puesto que no se sabe cuándo terminará éste, esta maniobra puede no dar resultado. Por otro lado, muy pocos estudiantes quieren realmente escapar al bizutage, a pesar de su carácter duro y molesto. Como indicaré más adelante, la aceptación del ritual por parte de sus víctimas y no sólo de sus oficiantes ha sido un hecho general, siendo las quejas y el rechazo muy minoritarios. La clase normal impartida por un profesor, en los casos en que se alternan bizutage y actividades escolares, tampoco representa un espacio de completa normalidad y de protección del bizut frente al acoso de los veteranos. Los bizuts se dan cuenta rápidamente de que no tienen ningún derecho de hablar o 
expresarse en el aula, regla que los veteranos hacen respetar amenazándoles con castigos después de las clases, a pesar de la presencia de los profesores.

El bizutage se lleva fuera de la institución - a los espacios públicos de la ciudad- mediante una serie de actividades ritualizadas, de las cuales la "procesión" es la más típica: un grupo de 50, 100 o más bizuts, encuadrado militarmente por los veteranos, deambula por las calles cantando varios himnos o llamadas al público, y andando en cadena. Cada uno pasa la mano izquierda entre las piernas para coger la mano derecha de la persona de atrás, lo que resulta ser una manera bastante incómoda y ridícula de caminar. Cada institución tiene sus tradiciones propias en cuanto a las sesiones públicas. Por ejemplo, en la Polytechnique se lleva a los bizuts los miércoles a reptar a través del alcantarillado de París ${ }^{12}$. Típicas en todos los bizutages son las "misiones", que han de realizarse en lugares públicos y que los veteranos atribuyen a los bizuts individualmente o en binômes. Algunos ejemplos son conseguir un certificado de virginidad en un convento de monjas, recaudar dinero pidiendo en la calle durante las manifestaciones públicas del bizutage (procesión, elecciones, etc.), ir en pareja a comprar preservativos a una farmacia $^{13}$, o vender hojas de papel higiénico en la calle. Se puede exigir a dos bizuts que formen una línea de cerillas en el suelo para rodear el Arco de Triunfo de París, o que limpien, uno por uno, los clavos de los pasos de peatones con un producto para el cobre y en medio de los coches. Otro ejemplo es mandar a un grupo a recaudar fondos para la "viuda del soldado desconocido"14, vestidos en pijama. Todas estas misiones se llevan a cabo bajo la vigilancia de un grupo de veteranos y ocupan varias horas del día. Se terminan con la apropiación del dinero (cuando lo hay) por los veteranos, que lo gastan ostensiblemente en los bares de alrededor, o lo reservan para la fiesta final. La reticencia a ejecutar las misiones o la falta de resultados se sanciona con nuevos castigos. Los rasgos comunes de estas misiones (sólo he proporcionado algunos ejemplos, pero la imaginación de los estudiantes es inagotable) son:

${ }^{12}$ No tiene carácter peligroso: buena parte del alcantarillado de Paris está abierto al público, y se visita de manera corriente.

${ }^{13}$ Antes del SIDA y de las campañas en favor de la utilización de preservativos, no era tan fácil hablar públicamente del tema, en todo caso mucho más embarazoso que hoy.

${ }^{14}$ Debajo del Arco de Triunfo se ubica la tumba del "Soldado Desconocido", muerto durante la Primera Guerra Mundial (1914-1918). A través de su tumba se honra, con una llama permanente, la memoria de los 1.400 .000 franceses muertos en aquella guerra. Se trata de un símbolo patriótico por excelencia, muy respetado en Francia. 
- el aspecto público: actúan como publicidad del bizutage para la institución, efecto reforzado por la dispersión de los alumnos en distintas zonas del barrio o de la ciudad;

- el aspecto humillante: las misiones se convierten en pruebas de superación de la timidez y de la vergüenza, en "exámenes" de desenvoltura;

- el aspecto absurdo: se subraya la insignificancia del sujeto mediante la misión, por su carácter irrisorio, inútil, casi imposible;

- el aspecto provocador: se bromea con algunos símbolos importantes de la sociedad (símbolos patrióticos, religiosos, civiles, etc.);

- el aspecto jerárquico: dada la carencia obvia de sentido del contenido de la misión, se destaca la importancia de la relación de poder que ella manifiesta con la dominación de los veteranos y la sumisión absoluta de los bizuts.

\section{Los actores del bizutage}

Como se ha hecho evidente hasta ahora, cualquier bizutage opone en primer lugar el colectivo de los veteranos de una institución determinada al colectivo de los recién llegados. Lo principal de todo el ritual parece consistir en imponer constantemente una relación jerárquica entre estos dos colectivos que, por otra parte, difieren muy poco entre sí: los veteranos tienen apenas un año o dos más que los bizuts y se encuentran en la misma etapa del sistema, pues todavía no han sido admitidos en una Grande Ecole. En medicina, son los de segundo o tercer año quienes actúan de oficiantes del bizutage, no los estudiantes más mayores, igual que en las escuelas superiores. Pero en ello consiste justamente la gran fuerza del ritual: en igualdad de condiciones, crea un estatuto, una personalidad social distinta y un rango superior para los que han pasado por él, lo cual lleva a la sumisión del recién llegado, que no sólo ignora la tradición y las reglas de la nueva institución en la que entra, sino que no ha pasado por la experiencia del bizutage.

El papel de veterano es un rol impuesto socialmente por el colectivo, que se apoya en la tradición, para obligar a cada uno a participar en el ritual. Por ejemplo, en la Polytechnique existe una comisión especial, llamada "Khomiss", que está compuesta de algunos veteranos, elegidos por votación, que se reúnen periódicamente para la organización del ritual y cuya misión principal, delegada por los veteranos que los han nombrado, consiste en seguir y perpetuar la tradición. Los demás compañeros deben aplicar sus instrucciones y llevar a cabo el programa de "celebraciones" que ellos han definido. Entonces, si no es fácil escapar al bizutage como bizut víctima de las novatadas, pruebas y castigos, tampoco es fácil para el veterano escapar al 
rol de oficiante y asumir su papel: hacer sufrir en las pruebas, imponer los castigos, a menudo por la fuerza, participar en las batallas y novatadas colectivas, organizar los aspectos materiales del bizutage, etc. Amparándose en el carácter colectivo y obligatorio de una tradición que debe aceptar para no acabar excluido de su propio grupo, el veterano tiende a desatender los eventuales aspectos crueles y violentos del ritual, resaltando el humor y la diversión.

Del mismo modo que existe una clasificación de las Grandes Ecoles, hay una clasificación de los institutos en los que se cursan las clases preparatorias, que acaban compitiendo entre sí. También se suele atribuir un rango más alto a ciertas ramas de preparación que a otras. Existe toda una jerga para designar estas distintas ramas: los prépas HEC (rama de ciencias empresariales) son designados de manera despectiva "épiciers" (tenderos) por los "taupes" (topos), es decir los miembros de las prépas matemáticas destinados a las escuelas de ingenieros. Durante el bizutage, varias alianzas y oposiciones se van a manifestar entre los estudiantes, marcando la solidaridad o los enfrentamientos entre grupos constituidos según diferentes divisiones. Los prépas HEC de dos o tres institutos pueden reunirse para afirmar su oposición a los "taupes" (prépas de matemáticas); $\mathrm{o}$, en otro momento, todas las ramas de un mismo instituto (veteranos y bizuts juntos) pueden formar un mismo grupo para "invadir" otro centro cantando la superioridad de su institución y gastando bromas y novatadas a los del otro instituto, lo que acaba generalmente en una gran pelea con agua, harina, huevos y otras municiones. Según los agrupamientos, determinadas canciones se eligen para afirmar la identidad y superioridad del grupo en cuestión (rama o institución).

Los profesores no intervienen en absoluto en el bizutage, como tampoco lo hace la administración de la institución. La actitud adoptada consiste en negar cualquier responsabilidad, volviendo la mirada para otro lado, con el argumento de que no disponen de los medios para controlar a los estudiantes organizados colectivamente. Ya desde la inauguración del ritual, profesores y miembros de la administración dejan a los veteranos tomar el mando, salen del espacio educativo, y abandonan su autoridad, anunciando en general que su único papel es asegurar la ausencia de abusos corporales y de desbordamientos. Resulta llamativa la ambivalencia de ese discurso, de la que son muy conscientes los estudiantes: detrás de sus declaraciones de "no-responsabilidad", la política de no-intervención de los profesores funciona, de hecho, como una tácita aprobación del bizutage. De ahí la expresión "ley del silencio" mencionada por los detractores del bizutage para denunciar esa actitud de apoyo implícito.

El público constituye otro actor importante del bizutage; ciertas partes del ritual están puramente destinadas a darse a conocer y reconocer ante la 
gente. Un bizutage que se desarrollara sólo entre los muros de la institución no cumpliría sus objetivos. Durante las sesiones que tienen lugar en la calle, se trata de identificarse y diferenciarse como grupo específico con respecto al resto de la sociedad, todo ello con cierto grado de provocación.

Dentro del público en general, hay que subrayar el rol de los padres de alumnos que, si bien no es directamente visible, sí influye: en general, salvo algunas excepciones, toleran con cierto humor las actividades un tanto "locas" a las que se dedican sus hijos, y sobre todo el sacrificio de varias semanas de tiempo "perdido" para los estudios. Ello se debe a su aprobación implícita de las características del sistema de enseñanza superior, que pasa por la aceptación de sus tradiciones. Distinguiendo entre dos casos típicos de padres, el fenómeno se entiende mejor. En un primer caso, los padres son ellos mismos fruto del sistema: pasaron por la carrera de las Grandes Ecoles (o medicina) y probablemente han experimentado un bizutage. Parece entonces muy natural que sus hijos pasen por las mismas vivencias, y su actitud de aprobación tácita corresponde a la reproducción de una tradición de la que ellos forman parte. Este caso es bastante frecuente, pues como subrayé antes, hay cierta tendencia, dentro de las mismas categorías sociales e incluso dentro de las mismas familias, a perpetuar la elección de una orientación determinada en los estudios. En el otro caso, los padres no proceden de este sistema de prépas y Grandes Ecoles, en el que sus hijos han podido ingresar; y la carrera de sus hijos representa para ellos un ascenso social. Sólo les queda tolerar el bizutage como una necesidad del sistema, que no entienden muy bien pero que forma parte del proceso de ingreso de sus hijos en un mundo social superior. Rechazar o condenar el bizutage significaría, en cierto sentido, tomar una posición en contra del sistema en su conjunto, dado lo fuertemente anclada que está la tradición; tal actitud sería contraria a la gratitud y a la satisfacción que sienten por el ascenso de sus hijos. Entonces, por sus intereses propios, los padres contribuyen de manera notoria a mantener esa "ley del silencio" que hace posible la perpetuación del ritual año tras año, acallando los elementos de sufrimiento que conlleva.

\section{Pruebas y castigos}

Tras la constante preocupación por imponer pruebas y castigos vejatorios al bizut, y por señalar su sumisión ritual a los veteranos, el bizutage manifiesta una extraordinaria creatividad de actividades, de palabras y de gestos a los que el contexto del ritual atribuye un significado concreto, difícilmente comprensible fuera de él. El principio de lo absurdo - desde un punto de vista exterior- rige esa creatividad; absurdo que cumple funciones importantes, como se desprenderá del análisis del bizutage como rito de inicia- 
ción. El típico "examen" individual o en binôme ilustra muy bien la utilización de lo absurdo. Consiste en una serie de preguntas codificadas por la tradición, a las que el bizut debe responder de manera también codificada por la tradición. La regla del juego se entiende rápidamente: el bizut debe auto minimizarse ante los veteranos, auto humillarse, "auto flagelarse", según la expresión figurativa de un informante. Por ejemplo, la primera pregunta puede ser "nombre y apellido: escríbelos en la pizarra". El bizut ejecuta la orden y, naturalmente, empieza a escribir su nombre con una mayúscula, en el centro de la pizarra. Reacción inmediata del tribunal: el carácter insignificante del bizut no justifica el uso de letras mayúsculas. El bizut tiene que borrar y escribir su nombre con minúsculas, en letra muy pequeña, en un rincón abajo de la pizarra. Si respeta una de las reglas, entonces los veteranos encuentran algún detalle que no les satisface, para prolongar la prueba. Después de otras bromas del mismo estilo, el bizut debe repetir frases, como por ejemplo "sólo soy una mierda". Debe siempre manifestar, bajo varias formas, su posición inferior, su ausencia de valor y de significado y, en cambio, repetir señales de respeto y de admiración por los veteranos. Cualquier actitud negativa o de rechazo se sanciona con un castigo que debe ejecutar enseguida.

Un ejemplo tomado de una clase de preparación a las escuelas de ingenieros ilustra otro aspecto del examen. En la pizarra, los veteranos dibujan una serie de jeroglíficos, representando todas las palabras que existen en francés para significar el pene. El bizut debe descifrar los jeroglíficos, y cuanto más tímido se muestra para pronunciar las groserías o más dificultades tiene para descifrar los dibujos, más se ríe el tribunal, más ridiculiza al "candidato" y más castigos impone a éste.

Fuera de los exámenes, los veteranos inventan multitud de órdenes más o menos absurdas para obligar a los bizuts a señalar su respeto y sumisión: llevar la cartera de un veterano, buscarle agua o ir a comprarle algo. A menudo, si el bizut se muestra sumiso y ejecuta la orden sin dificultad, se le castiga por ser demasiado obediente.

Cada bizutage tiene su propia serie de castigos tradicionales, con nombres específicos. En prépa HEC en Burdéos, por ejemplo, el castigo tradicional es la pompe (flexión) y sus distintas variaciones: parachutée (paracaídas: consiste en dejarse caer al suelo desde la posición vertical, terminando con una flexión), claquée (con palmada). Otro castigo consiste en andar como un pato (con las piernas flexionadas) y declamar al mismo tiempo algún refrán estúpido. Las pompes son también típicas de las preparatorias científicas, así como otro castigo que se llama culer (de la palabra cul, culo): consiste en recibir un cierto número de golpes de cinturón en el culo, estando el bizut en una posición inclinada llamada "Pi/2" (del número pi, fascinación 
de los matemáticos). Los veteranos distribuyen estos castigos con alegría; un castigo mal ejecutado, una serie de 10 pompes por ejemplo, lleva automáticamente a un castigo más fuerte: 20 pompes, luego 30 , y así sucesivamente. En otros casos, el castigo más frecuente es el "champú de huevos o de yogur": al bizut rebelde se le coge a la fuerza, y los veteranos le untan enteramente de huevos, yogur o cualquier producto que forme una masa pastosa, empezando por el pelo, que se restriega detenidamente. Los internos sufren unos castigos específicos, que consisten por lo general en impedirles dormir, sacarles de sus cuartos en medio de la noche, quitarles las bombillas para que no tengan luz, pasarles por la ducha en pijama, etc.

El hecho de pintar a los bizuts es una práctica frecuente. En el Quartier Lati $^{15}$ de París, se puede divisar a los estudiantes de prépa HEC y de Bellas Artes con el pelo multicolor o incluso enteramente cubiertos de pintura. En la Polytechnique, las salidas tradicionales del miércoles terminan con una operación de pintura: los veteranos untan a los bizuts de pintura amarilla o roja, según el color de la promoción. Siendo el amarillo y el rojo los colores emblemáticos de la escuela, cada año una promoción "roja" se encarga de iniciar a una promoción "amarilla", y a la inversa el año siguiente (la pintura es al temple y no resiste la ducha).

\section{Palabras y nombres}

Los ejemplos proporcionados hasta ahora muestran otra dimensión importante, que es el lenguaje creado y utilizado específicamente durante el bizutage. Los estudiantes dan nombres a las actividades y pruebas, a los castigos, a los grupos, utilizando principalmente dos fuentes: el mundo normal de los estudios que los veteranos ya conocen bien, y el mundo de la mili. Palabras del lenguaje escolar normal son transformadas con un cierto sentido del humor y una ironía evidente, como por ejemplo en las prépas matemáticas, donde muchos términos empiezan por "kh" para recordar el uso $\tan$ frecuente del griego en la ciencia y las matemáticas. La letra "pi" es otro ejemplo, así como las fracciones ( $3 / 2$ y 5/2) utilizadas para designar a los veteranos según sus años de prépa, o los términos Monôme y Binôme. Más allá del lenguaje, se trata de objetos o actividades (la asamblea en Monôme, el "examen" individual) tomados del mundo educativo y transpuestos de manera absurda y provocativa al contexto del bizutage. Lo mismo ocurre con el mundo militar, de donde proceden muchos de los castigos practicados durante el bizutage. La flexión ("pompe") es el típico ejercicio de entrena-

15 Barrio central que reúne a muchos estudiantes, incluso procedentes de otras zonas, debido a la presencia de las principales librerías universitarias. 
miento físico de la mili. La distribución de boinas de color y de insignias recuerda también al ejército. El hecho de marcar el ritual del bizutage con un lenguaje específico se traduce también por las canciones que los bizuts tienen que aprender y cantar constantemente, sobre todo durante las salidas colectivas o los enfrentamientos entre las distintas ramas o escuelas. Estas canciones afirman la superioridad del grupo frente a los demás alumnos de prépa. Por ejemplo, los alumnos de prépa HEC cantan colectivamente en el patio "Les agros ça pue, ça sent la charogne", es decir "los agros ${ }^{16}$ apestan, huelen a carroña". En la calle, se trata de hacerse notar y de provocar al público, cantando por ejemplo "Les cocus, au balcon!" (¡Cornudos, salid al balcón!).

Existe un rasgo común a muchos bizutages, que consiste en organizar, bajo una forma u otra, alguna ceremonia de atribución de nombres a los bizuts. En ciertos casos, por ejemplo, se organiza una elección de "Miss Bizut" y "Mister Bizut", imitando las elecciones de modelos en los concursos de belleza. Los tribunales están, por supuesto, compuestos de veteranos; mientras los candidatos son los bizuts, obligados a desfilar, a mostrar alguna parte de su cuerpo (ombligo para las chicas, musculatura de los hombros para los chicos) o tomar una actitud impuesta, bajo una lluvia de risas y bromas más o menos groseras. Los candidatos elegidos (un chico, una chica) llevarán el nombre de "Mister bizut" y de "Miss bizut", respectivamente, durante todo el resto del ritual.

En otros casos, se trata de atribuir un nombre individual a los bizuts, en una verdadera ceremonia de bautizo. Mientras cada bizut desfila, los carrés proponen todo tipo de apodos, en general basados en alguna particularidad física - gafas, sobrepeso, etc.-, cuanto más humillante, mejor. Los veteranos se ponen de acuerdo acerca de un nombre que se atribuye al novicio para todo el bizutage, en un ambiente general de risa y bromas. Los estudiantes de la Polytechnique tienen también una ceremonia de atribución de nombres, en la que algunos nombres corresponden a posiciones predeterminadas, que se atribuyen cada año. Por ejemplo, al más joven de la promoción se le bautiza como "Ti n'enfant", una manera infantil de decir "niño pequeño".

\section{Ritual y racionalidad}

El carácter aparentemente absurdo, ridículo, divertido, burlesco de los bizutages contrasta marcadamente con la reputación de seriedad, calidad y exigencia de las instituciones de enseñanza superior que mantienen esa tra-

\footnotetext{
${ }^{16}$ Estudiantes que preparan las escuelas de ingenieros agrónomos.
} 
dición, sobre todo teniendo en cuenta la duración del ritual, que implica una punción importante del tiempo previsto para la enseñanza en el curso escolar (2 a 4 semanas enteras o más, sobre un total de unas treinta semanas de docencia). El sentido común plantea, pues, la cuestión de la utilidad, del interés y de la racionalidad de tal conjunto de prácticas.

Por otra parte, desde el principio de este artículo utilicé la categoría de "ritual" para designar el tipo de fenómeno sociocultural al que pertenece el bizutage; aunque éste no tenga ninguna connotación religiosa, y se ubique en un plano estrictamente laico y secular, en el que, en nuestra cultura, se suele pensar que domina la racionalidad instrumental. Algunas reflexiones y discusiones que se han dado en antropología en torno al concepto de ritual pueden ayudar a entender mejor la aparente contradicción evocada entre la racionalidad de un sistema altamente perfeccionado de enseñanza superior y la "irracionalidad" de su más anclada tradición, el bizutage.

Edmund Leach define el ritual como "cualquier acto o sucesión de actos no instintivos y predecibles que no pueden explicarse 'racionalmente' como medio para la consecución de un fin" (Leach 1968: 383) ${ }^{17}$. El problema que plantea esta definición es que el criterio de racionalidad, como lo subraya el mismo autor, es culturalmente (o incluso individualmente) relativo. El antropólogo puede decidir que tal acto es ritual por irracional; pero el sujeto de la acción puede tener una visión opuesta. Del mismo modo, el neurótico compulsivo que se lava las manos continuamente puede hacerlo, en su opinión, por razones higiénicas muy racionales, mientras que el psiquiatra calificará su conducta de "ritual privado". Pero el ritual del que se ocupa el antropólogo tiene, por definición, una naturaleza social que se manifiesta por su carácter normativo y prescriptivo, y por el hecho de hacer intervenir a determinadas categorías de personas (La Fontaine 1984: 11-12). La mayor dificultad con el concepto de ritual, consiste, pues, en su relación con el concepto de racionalidad. La interpretación de un ritual como un conjunto de actos irracionales fomenta juicios morales y afectivos que limitan la comprensión de sus significados.

Siguiendo a Goody, que matiza el énfasis puesto por Leach en la "irracionalidad" del ritual, podemos definirlo como "un tipo de conducta normalizada (costumbre) en la cual la relación entre los medios y el fin no es intrínseca"18. El fin del bizutage no se relaciona de manera intrínseca con los

17 Es el criterio de racionalidad (entendido como existencia de una relación medio / fin) lo que permite, aquí, distinguir entre una actividad no ritual (o no ceremonial) y un rito. Una acepción más estrecha de la misma definición distingue entre ritual, ceremonia y costumbre, y define el ritual como "un conjunto de costumbres relacionadas directamente con las prácticas religiosas, mientras que ceremonia y costumbre se reservan para describir actividades de tipo secular" (Leach 1968: 384). Traducción mía.

${ }^{18}$ Citado en Edmund Leach (1968: 384). Traducción mía. 
medios utilizados, si se entiende como objetivo de la entrada en una clase preparatoria o en una escuela determinada la formación intelectual necesaria para los estudios. Más aún, parece ir en contra de este objetivo, desafiando la lógica de la eficacia instrumental. Pero probablemente, este objetivo no es el propósito que se "pretende" lograr a través del bizutage. Para descubrir la "lógica" del fenómeno, y comprender la fuerza con la que el bizutage se impone y se mantiene año tras año, hace falta recurrir a otras dimensiones del ritual resaltadas por los antropólogos.

Leach insiste en la dimensión comunicativa del ritual; parte de la observación de que cada acto humano tiene una doble dimensión: hacer algo, decir algo. "Casi todos los actos humanos que se dan en un medio cultural bien definido tienen estos dos aspectos, el técnico y el estético y comunicativo" (Leach 1968: 385). Se puede también llamar a estas dos dimensiones la "instrumental" y la "expresiva", siguiendo a John Beattie (1972: 100-101). Leach subraya que sea cual sea la definición utilizada, en lo que se suele llamar ritual "se destaca el aspecto estético y comunicativo sobre el técnico, aunque este último nunca desaparece" (Leach 1968: 386). Para el antropólogo la tarea consiste, pues, en descubrir el significado del ritual, que se desprende de una interpretación del "lenguaje social" expresado por las conductas culturalmente definidas. "El ritual sirve, pues, para recordar a los presentes qué posición ocupa exactamente cada uno de ellos en relación con los demás y en relación con un sistema más amplio" (Leach 1968: 386).

El ritual presenta entonces un vínculo con la configuración de las relaciones de poder en una determinada sociedad: "Este proceso de estilización tenderá a deformar la actividad secular en uno de estos dos sentidos: destacando el elemento ascético y representando la intensificación de la coerción formal, o destacando el elemento estático y representando la eliminación de la coerción" (Leach 1968: 388). Siguiendo esta idea interesante, el bizutage se puede entender como la estilización del aspecto comunicativo, en términos sociales, de un acontecimiento importante en la vida de los sujetos y de su entorno: el ingreso en el sistema de clases preparatorias o en una escuela superior. Entre las dos tendencias identificadas por Leach, se trataría claramente de la primera, es decir, de una cristalización e intensificación formal del poder y de la jerarquía, dentro del propio sistema de enseñanza y fuera de él, esto es, en relación con el resto de la sociedad. En efecto, como traté de mostrar, muchos signos y símbolos manipulados en el bizutage transmiten la idea de superioridad de los veteranos y de sumisión de los bizuts: la toma de poder general por los veteranos que se traduce en el control del espacio, del tiempo, de los movimientos y actividades de los recién llega-

" dos; el "examen" individual o en binôme; las órdenes y misiones absurdas; los castigos físicos. 
Por otra parte, Victor Turner subraya que el ritual es un "mecanismc que periódicamente convierte lo obligatorio en deseable" y hace que "el fastidio de la represión moral" se convierta en "el amor a la virtud" (1980: 33). Aplicando esta interpretación al caso del bizutage, su dimensión ritual sería justamente lo que permite entender por qué los individuos aceptan en general someterse a la obligatoriedad de una serie de prácticas bastante desagradables, y por qué los veteranos se empeñan tanto en cumplir su rol apenas un año después de haber sufrido la prueba como víctima. Es la primacía dada a lo colectivo, al grupo por encima del individuo, la que facilita la eficacia del mecanismo ritual. Esa dimensión colectiva - la formación de "un solo cuerpo"- destaca en las asambleas en que se agrupan todos los bizuts y la palabra "monôme" para designarlas ${ }^{19}$; destaca también en la boina y la insignia, claros símbolos de pertenencia al grupo y de identidad colectiva frente a otras categorías, en las canciones y las procesiones ruidosas en la calle, en el hecho de andar en cadena, en la comensalidad y la fiesta final, y también en las recaudaciones y la utilización colectiva del dinero.

\section{EL BIZUTAGE COMO RITO DE INICIACIÓN}

Al mirar el bizutage como la ritualización del acontecimiento importante que representa, para un joven francés, la admisión en una prépa o Grande Ecole, surge evidentemente la idea de tratarlo como un "rito de paso" según la famosa fórmula introducida por Van Gennep (1986). La idea central de Les Rites de passage es que la vida individual consiste en pasar de unos estados a otros, de unas categorías sociales a otras. Existe un paralelismo entre los cambios de categorías sociales y el franqueamiento de umbrales o fronteras que a menudo son objeto de rituales de paso. En las sociedades primitivas, según el planteamiento de Van Gennep, dichas categorías se definen ante todo en función de las edades y de las ocupaciones, y la necesidad de ejecutar ceremonias para el paso de una a otra se explica por la vinculación de las separaciones sociales con lo sagrado. Por ello las ceremonias del nacimiento, de la infancia, de la pubertad, del noviazgo, del matrimonio, de la paternidad, de la iniciación, de los funerales, etc., tienen una estructura común. Se descomponen todos en ritos de separación, que marcan el abandono de la categoría social previa, ritos de margen destinados a representar y efectuar la transición, y ritos de agregación, que aseguran la incorporación a la nueva categoría social. Sin embargo, la importancia relativa de cada subtipo puede variar de un ritual de paso a otro. Por ejemplo, los ritos de separación están más desarrollados en los funerales, mientras que en el matri-

19 Término tomado del universo matemático, que significa unidad, carácter unitario. 
monio el énfasis se pone en los ritos de agregación. Los ritos de margen pueden tomar una importancia menor o mayor, hasta incluso dominar la secuencia entera del ritual, como en el caso del noviazgo, que llega a ser en sí mismo una posición social marginal entre la anterior (soltero/a) y la posterior (casado/a). Los ritos de iniciación de los varones en las sociedades tradicionales revelan una estructura común en la que la marginalidad, entre la separación del mundo de la niñez y la agregación al mundo de los hombres adultos, alcanza formas espectaculares por su duración y su dureza, como lo muestran los trabajos de Godelier (1982), Jean La Fontaine (1984) o Victor Turner (1980).

Siguiendo la propuesta de Van Gennep, los elementos etnográficos del bizutage pueden organizarse según las tres fases (preliminar, liminar, y postliminar) que articulan un rito de paso.

\section{Ritos preliminares o de separación}

La principal manera de ritualizar la separación se encuentra en la ceremonia de comienzo del bizutage, con el "paso de mando" de la institución de los profesores y miembros de la administración a los veteranos. La primera asamblea marca la separación, al sacar a los alumnos del ambiente escolar -aulas, clases, libros-y echarles colectivamente en el ritual. El robo de objetos personales se puede también incluir en la etapa preliminar, así como las irrupciones en los cuartos de internados: estos gestos parecen significar, para el bizut, la pérdida de su identidad "normal". Los veteranos le despojan - provisionalmente- de sus objetos personales: cartera, libros y cuadernos, DNI y papeles personales, y de su espacio privado, los cuales le vinculan con su vida social fuera del bizutage, y con su estatus de alumno, hijo o hija de una familia. Sin embargo, los ritos preliminares no parecen muy desarrollados en el bizutage. La hipótesis más consistente para dar cuenta de ello es que la separación del mundo "normal", anterior al bizutage, ya se ha realizado de hecho al comienzo del ritual. Los bizuts ya han franqueado una doble frontera, espacial y social, que les separa de su mundo de origen. La frontera espacial la constituye la puerta de la nueva institución ${ }^{20}$. La frontera social consiste en la entrada en un nuevo ciclo de estudios después de una selección dura y en un cambio de status: ya no es alumno de secundaria, forma parte de un grupo específico, los prépas. A menudo se ha separado también de su entorno social habitual para estudiar en otra ciudad.

${ }^{20}$ Los alumnos no suelen cursar las clases preparatorias en el mismo instituto que los estudios secundarios, y si es el caso, hay siempre una separación del espacio reservado a los prépas, y una puerta de entrada distinta a la de los alumnos de secundaria. 


\section{Ritos liminares}

Para Leach, la fase liminar o de margen, que sigue a la separación en los ritos de paso, consiste en volver a la persona temporalmente "anormal", en un tiempo anormal; de ahí, no sólo el mantenimiento del iniciando apartado del resto de la sociedad, sino también las restricciones, prohibiciones y prescripciones especiales que indican la "anormalidad" (Leach 1978: 107-108). Los bizuts se encuentran, efectivamente, inmersos en un tiempo y un espacio especiales, con reglas particulares. Los símbolos rituales del bizutage resaltan una serie de contrastes con respecto a los valores, normas y prácticas habituales de la vida académica de las clases preparatorias y Grandes Ecoles, o de la vida social a la que están destinados los alumnos. Se evidencia entonces que muchos aspectos del bizutage son manifestaciones de "locura", de inversión de reglas, normas y prohibiciones. Esas inversiones se pueden representar por pares de términos opuestos; el primer término se refiere a la situación "normal", y el segundo a la situación del bizutage:

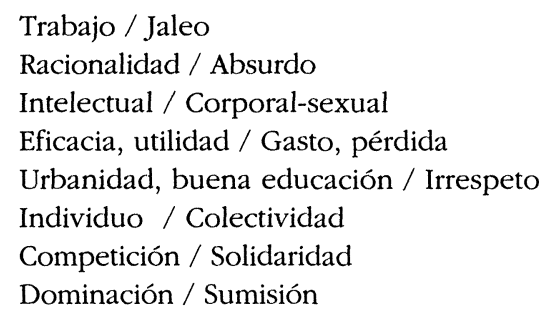

Como lo subrayan los antropólogos, la representación de la muerte y del renacer es también una característica común a los ritos de paso, asociada a la fase de margen, y se resalta particularmente en las iniciaciones. Existe un paralelismo entre separación / agregación y muerte / renacer, que constituye una representación frecuente de comienzo / fin: fin de una categoría social (y de un tiempo social), comienzo de una nueva categoría social (y nuevo tiempo social) (Leach 1978: 109; Van Gennep 1986: 91-117).

En el bizutage, los símbolos de pérdida de identidad y de aniquilación del individuo parecen indicar un estado de "no-persona", de "no-existencia", equivalente a una muerte simbólica, como lo muestra de forma destacada el típico "examen individual" descrito más arriba, o la humillación y ridiculización propias de las "misiones". Los nombres individuales dejan de ser utilizados, el bizut puede verse despojado de sus objetos y papeles y, en los internados, las irrupciones en el espacio privado del cuarto, las salidas en pijama, significan del mismo modo la imposibilidad de afirmar su identidad personal. El pijama se asemeja a un traje de preso, borrando las distinciones 
entre los novatos. En contrapartida, la atribución de nombres específicos para el bizutage es un fenómeno frecuente, como por ejemplo en las elecciones y las ceremonias de nombramiento.

Por otra parte, hay ritos en el bizutage que consisten en el paso del bizut a través de algo; por ejemplo, un aula pequeña con los ojos tapados. Aquí, el hecho de hacer girar al bizut cegado sobre sí mismo —es decir, de desorientarle - representa la oscuridad, las tinieblas, un mundo desconocido. Hacer reptar a los bizuts por el alcantarillado de París también puede significar el paso a través de lo oscuro y lo desconocido, para nacer de nuevo a la luz del día. En esos símbolos se puede ver una representación de entrada en una matriz, y de salida / nacimiento. La desnudez, impuesta frecuentemente en los internados, tendría, como lo indica V. Turner (1980: 110), una doble referencia: muerte y nacimiento, desnudez del cadáver y estado virgen del recién nacido.

Asimismo, el bizutage escenifica una estructura social propia de la transición: relación absoluta de dominación / sumisión entre los veteranos y los bizuts, hasta el punto que incluso la rebelión dentro del ritual se utiliza para reforzar esa relación, como indicaré en seguida. Es la igualdad social perfecta de los bizuts entre sí. Además, lo que los iniciantes representan se puede claramente interpretar como la tradición propia de la institución. Los veteranos se constituyen en colectivo sólo para el bizutage - pues en tiempo normal domina la competición entre ellos- y su papel reside en reproducir los gestos tradicionales, en poner en escena la misma expresión que la tradición impone. Los bizuts no obedecen a personas: obedecen a la tradición y sus discursos así lo muestran.

Como lo señala Victor Turner (1980: 107-109), a la situación marginal del iniciando se asocian las ideas de ambigüedad y de suciedad, que se vinculan con la "invisibilidad estructural de las personas liminares". Los novicios en un rito de iniciación ya no están clasificados en su categoría previa, al tiempo que todavía no están tampoco clasificados en un nuevo estado social. Retomando la idea de Mary Douglas en Pureza y Peligro (1973), Turner interpreta la situación liminar como ambigüedad, confusión de las categorías habituales, lo que lleva a la idea de contaminación. Simbólicamente, los iniciandos no son nada o son dos cosas a la vez: asexuales o bisexuados, muertos o recién nacidos, en estado de "pobreza sagrada".

Muchas expresiones del bizutage aluden a características ambiguas atribuidas al iniciando: es un "niño", es virgen (no es un verdadero hombre), no ha sido diferenciado sexualmente. El ritual se encarga de volverlo simbólicamente sucio, contaminante, y de señalar la marginación, la separación: la pintura o el "champú de huevos" hacen del bizut un "intocable", que inspira asco y le colocan en un estado "anormal". En sus relaciones con el públi- 
co, el bizut se halla apartado: su grosería, su suciedad, hacen que no pueda mezclarse con la gente normal, y cada vuelta al mundo cotidiano - el trayecto diario a casa en el transporte público- constituye una prueba más.

\section{Ritos postliminares}

Las representaciones de lo colectivo, de la solidaridad del grupo, de la pertenencia a un solo cuerpo, son aspectos subrayados a lo largo del ritual: canciones y procesiones, nuevo lenguaje común, boina e insignia, andar en cadena. Pero la agregación al grupo encuentra su cumbre al final del bizutage con los últimos gestos y la fiesta colectiva. La comensalidad —que, según Van Gennep (1986: 39), representa claramente un rito de agregación, "de unión propiamente material [...] un sacramento de comunión"- es la ocasión para un cambio profundo: una transformación "ontológica" del bizut, que ya se encuentra en su nuevo estatus de estudiante de prépa o de una escuela. También indica la abolición de la jerarquía propia del ritual, entre veteranos y bizuts. En efecto, durante la fiesta las dos categorías se mezclan, se vuelven a utilizar los nombres propios, se establecen contactos personales usuales en una situación social de comensalidad, los colectivos bizuts / veteranos se disuelven.

\section{Fabricar verdaderos hombres}

Si el ritual, para retomar la expresión de Leach (1968), es una comunicación social, tendríamos que poder formular su "mensaje", expresar lo que el bizutage, en su conjunto, "hace" y "dice". La interpretación estructural que acabamos de presentar permite considerar el bizutage como un "rite de passage" compuesto de las tres etapas: las de separación, margen y agregación, con especial énfasis en los ritos liminares. Lo cual muestra la función principal del ritual: expresar y asegurar un cambio de estatus o rol social. Se trata del cambio de simple alumno de instituto al estatus de estudiante del sistema de Grandes Ecoles, un cambio significativo en términos del futuro a que se destina la persona: en la medida en que será capaz de superar las pruebas del sistema (oposiciones), podrá ocupar una posición importante en la sociedad y formar parte de una elite.

El bizutage, entonces, parece encargarse de la formación "moral" o "espiritual" del estudiante, aspecto que el sistema de enseñanza no asegura directamente. El ascetismo, la obediencia a los veteranos — que, al mismo tiempo, son los iguales de los recién llegados- y las pruebas físicas y morales, constituyen una experiencia particular, una vivencia que produce el cambio interno necesario. Por ello, se trata de una verdadera iniciación más que de un simple rito de paso. 
En las Escuelas de Artes y Oficios, el bizutage se llama "usinage", palabra tomada del lenguaje industrial, que significa fabricar mecánicamente una pieza metálica. La palabra misma indica perfectamente el significado implícito del ritual: "fabricar" a los hombres aptos para formar parte de una cierta categoría, de una determinada elite. Por ello, los neófitos, recién llegados al sistema, tienen que asimilar un conjunto de valores y representaciones que el ritual se encarga de expresar y transmitir, valores y representaciones que llegan incluso a tomar la primacía sobre el contenido de los estudios: importancia de la tradición, de la solidaridad del grupo, necesidad de mostrar valor y resistencia para su éxito en el sistema, adquisición de un lenguaje y de una identidad común...

Para entender la idea de "fabricar" (usiner) mediante el bizutage, es necesario referirse a una observación fundamental hecha por los estudiosos de los rituales de iniciación: que el rito de paso no sólo marca el paso sino que hace el paso. Los símbolos del ritual "están esencialmente implicados en el proceso social [...] el símbolo ritual se convierte en un factor de la acción social, una fuerza positiva en un campo de actividad" (Turner 1980: 22). Este aspecto lo podemos llamar, siguiendo a Austin y otros filósofos del lenguaje de la escuela de Oxford, la dimensión performativa del ritual. No se limita a expresar o representar algo, sino que hace algo, se imprime en el individuo (incluso en su cuerpo), fabrica una experiencia vivida. Los rituales que corresponden a las "crisis vitales" del individuo marcan también cambios en las relaciones de todas las personas vinculadas con él: la madre de una mujer que da a luz a un niño se convierte en abuela, el marido en padre... y los cambios afectan incluso a las relaciones políticas y económicas (transmisión y herencia de cargos, privilegios, bienes, propiedad). El ritual se centra en el "gran momento" de un individuo o un grupo, pero constituye también un "gran momento" para el resto de la sociedad. Citando a Radcliffe-Brown, Turner recuerda que los funerales se ocupan más de los vivos que de los muertos (Turner 1980: 10).

El ascetismo, que se define en general como una regla de vida, un conjunto de ejercicios físicos y morales destinados a la mejora de la vida espiritual, es otra característica común de los rituales de iniciación. En el caso estudiado aquí, el bizut debe soportar, sin queja ni signo de debilidad, varias dificultades físicas y morales a lo largo del ritual. Se trata de aguantar el dolor físico (en los castigos como la operación de culer, de comer mostaza) y las molestias (ducha en medio de la noche en pijama, batallas de agua y de huevos), de superar la fatiga y mostrar su resistencia (flexiones, ausencia de sueño para los internos), de superar su timidez o vergüenza, de atreverse, y de tener imaginación y desenvoltura. Aguantar, resistir, ser fuerte, ser valiente son los leitmotiv del bizutage. 
Se trata realmente de la "producción de grandes hombres", para retomar la expresión acuñada por Maurice Godelier para designar los ritos de iniciación entre los baruya de Nueva Guinea (1982). Podemos incluso ir más lejos en la equiparación, si tomamos la palabra "hombre" en sentido de varón y no de ser humano genérico. A pesar de la presencia de una minoría femenina que pasa por el bizutage, los valores que en él se expresan son muy "masculinos", es decir, se asocian claramente con imágenes de virilidad en nuestra sociedad: la fuerza física, la hombría, la capacidad de aguante, el coraje moral, la resistencia al dolor, la afirmación de la sexualidad varonil. Al preparar un grupo de jóvenes destinados a ocupar, en el futuro, posiciones dominantes en la sociedad, el modelo moral que se utiliza es el de la virilidad. En efecto, el "machismo" general de los rituales de bizutage destaca con suficiente claridad en las descripciones. Las representaciones fálicas son frecuentes: los dibujos durante el examen individual, los múltiples nombres del pene, la prueba del plátano en el rito final. Entre las misiones, algunas tienen un carácter sexual explícito, como la solicitud de un certificado de virginidad o la compra de preservativos. Más allá de las bromas y de las pruebas de valor que representan, parecen significar para los bizuts varones el paso de un estado de "chica" (virgen, inocente) al de "verdadero macho" durante el ritual. Muchos aspectos que aluden al servicio militar o al mundo del ejército juegan el mismo papel, ya que, como lo muestra J. Zulaika (1989), la mili es esencialmente un ritual de iniciación a los valores de hombría y masculinidad. O, para tomar otro ejemplo, entre los Marines en Estados Unidos, para transformar a los reclutas en killers es necesario primero "matar a la mujer que cada uno lleva dentro", como lo dice un protagonista de la película Full Metal Jacket, de Stanley Kubrick. En el caso de presencia de chicas en el ritual, la elección de Miss bizut podría ser un equivalente femenino: está indicando a las chicas cómo volverse "mujeres de verdad", es decir, cómo ser objetos de placer para los hombres. Resulta llamativo que, en las ramas mixtas, las relaciones de pareja entre bizuts o entre veterano y bizut se prohiban totalmente durante el bizutage (por lo menos en sus manifestaciones exteriores), mientras en cambio, durante la fiesta final, se permita e incluso se fomente el ligue. Se puede subrayar además una aparente relación entre las características del bizutage y la tasa de representación femenina en la institución: cuanto menor es la representación femenina, más "viril", más duro, se hace el bizutage. En cambio, las instituciones que conocen una mayor presencia de mujeres parecen haber adaptado paulatinamente su bizutage para fundarlo en una especie de substrato común, más mental que físico y corporal, en el que ambos géneros pueden encajar, aunque sigue apoyándose, a pesar de todo, en valores masculinos.

Por otra parte, si el bizutage no marca los cuerpos de manera definitiva, 
indeleble, las operaciones de pintura y el hecho de untar al bizut con varias sustancias, así como las boinas e insignias, constituyen probablemente un equivalente, provisional, de las prácticas de mutilación, escarificación y marcas corporales que encontramos en muchos rituales de iniciación en las sociedades primitivas (Van Gennep 1986; La Fontaine 1984). Tienen aparentemente la misma triple función: hacer pública la iniciación y el nuevo estatus del iniciando (lo importante es que el estado físico del bizut sea visible para el resto de la sociedad, es decir fuera de la institución); imponer una experiencia de cambio, de transformación, vivida hasta en su propio cuerpo; marcar la marginación, la separación (estado sucio y "anormal" del bizut).

Todos esos elementos permiten afirmar que el bizutage constituye un verdadero ritual de iniciación, siguiendo la tradición de los estudios antropológicos en las sociedades "primitivas", y teniendo en mente que dichos ritos de iniciación marcan un cambio social antes que natural y conciernen a un conjunto de iniciandos, más que a personas individuales.

\section{La experiencia iniciática del bizutage}

En los ritos de iniciación se pretende transmitir conocimientos y poderes que son exclusivos de los iniciados (La Fontaine 1984: 13-21). Pueden ser los misterios de una sociedad secreta, o los conocimientos relativos a la religión y la mitología - por ejemplo la naturaleza de los tambores entre los Baruya (Godelier 1982), de las máscaras Kachina entre los indios Pueblo (La Fontaine 1984) - o simplemente consistir en la experiencia misma de la iniciación, que se presenta, en cierto sentido, como no comunicable, como misteriosa. Este último aspecto resalta particularmente en el caso de la mili, donde los "iniciados" insisten una y otra vez en que no se puede saber en qué consisten la mili y las novatadas si uno no ha pasado por ello (Zulaika 1989: 131).

En el bizutage, la experiencia se presenta también con esa dimensión "misteriosa", difícilmente descriptible y transmisible, pero que deja huellas en la persona y vuelve la experiencia inolvidable. Según los comentarios de los informantes sobre su vivencia de la iniciación, el bizutage parece producir un cierto número de efectos morales, que tienen que ver con la situación específica del estudiante de clases preparatorias: desarrollo de la fuerza moral necesaria, fortalecimiento de la cohesión del grupo y sentimiento de pertenencia a una categoría especial, a una tradición.

Al mismo tiempo, los discursos expresados tienen probablemente una cierta función de justificación y de racionalización para hacer verlo todo bastante positivamente y minimizar la dureza del ritual. Entre otras racionalizaciones, es frecuente considerar que el bizutage que se practica en otras 
instituciones es más duro que el que uno ha sufrido. Los rumores que circulan en la época del ritual entre los prépas afirman que las pruebas de medicina son las más severas, que allí se producen accidentes, y que los veteranos acosan duramente a las chicas, por ejemplo escondiendo trozos de cuerpo humano en sus bolsos para asustarlas. O bien es otra rama a la que se acusa de practicar un bizutage fuerte: los estudiantes de Bellas Artes tienen la reputación de practicar un bizutage "bard", muy duro: como dejar a las chicas en pelota, o pintar o encerar el pene de los bizuts. Dos instituciones en particular tienen, según otros rumores, el bizutage más duro; de SaintCyr se dice que sus alumnos sufren mucho físicamente y de los Gadz'Arts (los estudiantes de la Escuela de Artes y Oficios) que tienen un bizutage muy tradicional y cruel de dos meses de duración, en el que "desvisten a los bizuts y les enceran los cojones".

Los relatos de los informantes destacan a menudo una cierta ambivalencia de sentimientos hacia su propio bizutage, una mezcla de impresiones opuestas. Las partes negativas de la vivencia corresponden al disgusto, a las molestias casi permanentes, a veces al dolor producido por los castigos físicos, a la indignación frente a la estupidez, a la humillación personal. Un testimonio da cuenta de un fuerte sentimiento de estupor y pasmo al principio del ritual: "Tenía la impresión de haber llegado a un mundo 'sin fe ni ley', a una jungla". El pasmo se ve reforzado al darse cuenta de la actitud de aprobación implícita de los profesores. En otros casos hay pocas pruebas o castigos físicos, y el aspecto negativo mayor lo constituye el frecuente sentimiento de humillación y de vergüenza. Sin embargo, ninguno de los testimonios habla de experiencias realmente traumatizantes, ni da cuenta de violencias físicas graves o de pruebas que hayan podido dejar marcas indelebles. Ello viene corroborado por la escasez de quejas o denuncias relativas a hechos de bizutage. La mayoría de las víctimas presentan el dolor y la humillación que han sufrido como fácilmente superables, y subrayan el carácter formador de la vivencia, a veces con un tinte de heroísmo. También, entre los aspectos positivos, se destaca el carácter divertido de toda la experiencia: "En el fondo, representa un buen recuerdo". Es un período de fiesta, de risa, en el que se estudia poco, uno se divierte y se arma mucho jaleo. Según los informantes, el hecho de tener la buena perspectiva y actitud de considerar el ritual como una broma y no tomárselo demasiado en serio es la clave para no pasarlo demasiado mal. Se subraya que el bizutage representa una experiencia más dura y negativa para los rebeldes, los recalcitrantes, a quienes los veteranos infligen más pruebas y castigos.

Se puede observar en los relatos una evolución, un cambio bastante nítido, entre la vivencia del comienzo del bizutage y lo que uno siente al final. Se ha producido una transformación, que puede ser analizada en tres 
aspectos: la adquisición de cierta fuerza moral, la creación de vínculos de solidaridad con los participantes en el ritual y la institución de una diferencia, de una "distinción".

\section{Adquirir fuerza moral}

Como subraya La Fontaine (1984: 19), en las iniciaciones en general se pone a prueba "las cualidades de los candidatos y al mismo tiempo las pruebas aportan un elemento esencial de la experiencia total que efectúa el cambio en ellos". El bizutage tiene la virtud de muchas de las experiencias iniciáticas que dejan, al salir de ellas, un sentimiento de "lo he hecho, lo he superado" y de que se ha reforzado la personalidad del sujeto. Ese sentimiento de fuerza moral se expresa así por un informante: el hecho de ver a otros bizuts que "jamás habían salido de casa" pasarlo mal mientras uno consigue aguantar las pruebas produce la seguridad de tener una cierta fortaleza de carácter, una cierta experiencia en la vida. En muchos casos, es más bien a través del propio bizutage como se desarrolla un sentimiento de mayor fuerza moral, de mayor independencia y capacidad para aguantar las pruebas o para desarrollar estrategias de escape, en definitiva para adaptarse a las exigencias del sistema social en el que uno está inmerso.

\section{Producir la solidaridad}

Al sufrir las novatadas y las pruebas juntos, los bizuts desarrollan sentimientos de solidaridad, que se traducen en orgullo: "orgullo de formar parte de la prépa HEC del Lycée X. Era el mejor instituto de la región, el más prestigioso, con los mejores resultados en las oposiciones. Atraía estudiantes de toda la región...". Por otra parte, el carácter tan evidentemente absurdo de las pruebas, misiones y castigos, favorece la diversión y el establecimiento de una connivencia con los veteranos, basada en la risa. Cito a un informante: "El hecho de que los carrés exageraban lo absurdo provocaba la risa de los bizuts y una cierta sintonía, simpatía, entre nosotros y ellos: el hecho de compartir algo juntos. Estábamos lejos de las relaciones víctima/ verdugo. La paradoja y lo absurdo llevan al humor, que permite aguantar. Aguantar el bizutage pero también, luego, las condiciones de la prépa (trabajo intenso, fuerte dedicación personal) e incluso el posible fracaso en las oposiciones. Quizá en el bizutage se halla la búsqueda de una comunidad de sufrimiento".

He señalado la alta selectividad y competitividad de las instituciones en las que se da el bizutage. En efecto, el ritual afecta a un grupo de estudian- 
tes que ya han sufrido una primera selección, pero todavía sin haber llegado al final del proceso selectivo. El bizutage crea y mantiene la solidaridad del grupo en un contexto altamente competitivo, que tendería a producir efectos opuestos (individualismo). La solidaridad se manifiesta, además, a distintos niveles:

-En el conjunto de los miembros del sistema de Grandes Ecoles frente al resto de la sociedad (que incluye a los estudiantes del sistema universitario), mediante una distinción nítida entre los que pasan por el bizutage y los que no pasan por él. Godelier (1982) llama la atención sobre este punto: la relación social que reproduce y refuerza la iniciación masculina de los baruya es la de dominación de los hombres (todos los hombres), que pasan por el ritual, sobre las mujeres (todas las mujeres), que no pueden pasar por él. La exclusión de la parte femenina de la sociedad del ritual de iniciación traduce precisamente la relación de dominación que el rito expresa y fomenta. En este sentido, el bizutage constituye, al igual que muchos ritos de paso, un "rito de institución", según la expresión de Bourdieu (1985: 78-86), que consagra y legitima una "diferencia constante entre aquellos a quienes concierne el rito y aquellos a quienes no concierne" (ibid.: 78).

- En cada promoción anual, que se opone a la promoción previa que la está iniciando, y luego se opondrá a la siguiente; la sumisión a la tradición permite imponer una solidaridad que el sistema de enseñanza no permite normalmente, pero que se necesita para que funcione su rasgo esencial, el corporativismo. Y ¿cómo crear mejor una solidaridad entre individuos que compiten entre sí, que obligándoles a someterse colectivamente a la dominación ritualizada de otro grupo?

- Dentro de cada rama.

- Dentro de cada institución.

Con respecto a estos dos últimos niveles, la solidaridad se hace necesaria debido a la competitividad del sistema de Grandes Ecoles. Para mantenerse, este sistema impone una exigencia de "ser el mejor", no sólo a cada estudiante, sino también a cada institución o rama que, en la carrera por la reputación, intenta superarse, ser mejor que las demás. Dicha carrera por la reputación encuentra su homología perfecta dentro del bizutage.

\section{Instituir la distinción}

Hablando de la solidaridad que produce el bizutage entre todos aquellos que pasan por la iniciación, evoqué su función legitimadora y de institución de una línea de demarcación social entre aquellos que pasan por el ritual y aquellos que nunca pasarán por él, siguiendo la idea de Bourdieu citada más 
arriba. Ello permite entender mejor la verdadera acción transformadora del ritual, no sólo en términos de experiencia moral, física o espiritual del iniciado, sino en términos de eficacia simbólica de un proceso social, que actúa sobre lo real. En efecto, el ritual produce una doble transformación. En primer lugar, porque transforma la representación que el resto de la sociedad se hace de la persona consagrada por el ritual, y todos los aspectos públicos del bizutage tienden a producir y reforzar la distinción del miembro del sistema de Grandes Ecoles con respecto a otros sectores sociales. Esa nueva representación, esa consagración, se traduce por las actitudes que los distintos actores sociales mantienen con respecto a él, durante el propio bizutage y después: se toleran sus provocaciones y manifestaciones excesivas, reconociendo que forma parte de una categoría especial, es decir los futuros miembros de la elite de la nación. En segundo lugar, porque transforma la representación que el propio bizut se hace de sí mismo, y las conductas que el ritual le obliga a adoptar para conformarse a esa representación: la de un miembro de una categoría superior, distinguida, destinada en el futuro a ocupar una posición privilegiada, de poder. Los aspectos evocados anteriormente - pruebas, castigos, sufrimiento físico, humillaciones, etc.- participan de esa producción de personas excepcionales, "distinguidas" según la palabra de Bourdieu, mediante un verdadero proceso de "incorporación", es decir, de inculcación a través del propio cuerpo.

Para el estudiante del sistema de Grandes Ecoles, el bizutage se considera implícitamente como un paso obligatorio para "acceder a un estatus para cuya consecución uno ha empleado tantos esfuerzos". Es, en cierto modo, la ley del sistema, el precio que hay que pagar para conseguir el estatus social del grupo. Las palabras de un informante muestran perfectamente cómo el ritual instituye esa diferencia social, esa distinción. Para él, el bizutage ayuda a "estructurar las relaciones con el mundo exterior": cuando, por ejemplo, reconoció hace poco en la televisión al director de una empresa importante que él mismo había iniciado muchos años antes, y que no había visto desde aquel entonces, lo que dominó fue su sentimiento de que eran iguales, pertenecían al mismo mundo, habían pasado por la misma prueba, e incluso que, al haber iniciado a esa persona, en cierto modo, había contribuido a prepararlo para estar donde estaba ahora, en una posición alta en la sociedad.

En los rituales de iniciación existen mecanismos que obligan al iniciado a reconocer su cambio de estatus y sus nuevas obligaciones, como los juramentos, que tienen como esencia comprometer al individuo, vinculándolo a otros miembros (La Fontaine 1984: 19). En el caso del bizutage, la obligación principal que se asocia con el hecho de haber sido "bizuté" es la participación, como veterano oficiante, en el bizutage de los nuevos iniciandos. Luego, esta obligación se mantendrá, aunque de manera más difusa, en el 
espíritu corporativista entre titulados, que se manifiesta a través de las asociaciones de antiguos alumnos.

A este respecto, es interesante observar el contraste entre la facilidad con la que se habla de la experiencia del bizut - capacidad de percibirla positivamente, de destacar aspectos divertidos y formativos en la vivencia del lado del iniciando- y la dificultad y reticencia para hablar de la experiencia de iniciante. El olvido que ciertos informantes evocan, con respecto a su rol de oficiante, puede ser una estrategia cómoda para evitar esa dificultad. En otros casos, la cuestión se oculta tras el aspecto colectivo e impuesto por la tradición, la diversión y el buen ambiente. En ciertas entrevistas se expresa un sentimiento difícil, un rechazo de la imagen de "veterano duro" que inspira miedo y rebelión a los bizuts; imagen impuesta por su obligatoria adscripción al grupo de veteranos. La experiencia de iniciante puede ser entonces más negativa que la de iniciando, según las circunstancias y las condiciones personales.

\section{Bizutage $y$ rebelión}

El último aspecto destacable del bizutage, que quiero comentar aquí, es el hecho de que la protesta en contra del orden social establecido se permite e incluso se fomenta. Ya señalé las múltiples formas de inversión de reglas y normas sociales implícitas en el ritual, incluso la ironía con respecto a los símbolos importantes de la sociedad; ello se acompaña de la aprobación tácita por parte de los dirigentes del sistema de enseñanza.

La práctica misma del bizutage produce naturalmente la rebelión de los bizuts, la cual forma parte del ritual, como se ha visto con las peleas colectivas y los intentos sistemáticos para escapar de las pruebas y misiones, lo que a su vez da lugar al reparto de castigos. Ello representa una especie de rebelión estructural dentro del propio bizutage, que se ritualiza a su vez y se incorpora, sin constituir una amenaza para el sistema. Se trata de una conducta de rebelión incluida dentro de las reglas del juego y que no conduce a una concepción negativa del mismo; muy al contrario, lo hace más divertido, y permite la expresión de la oposición frente al poder de los veteranos. Se puede decir que no habría un verdadero bizutage sin la rebelión de los bizuts.

Max Gluckman y Georges Balandier ${ }^{21}$ coinciden en su interpretación de las representaciones de rebelión que aparecen en muchos rituales. Según ellos, el ritual exhibe o teatraliza la protesta y la rebelión, poniendo énfasis en los

\footnotetext{
${ }^{21}$ Max Gluckman (1973), en particular, el capítulo "The Licence in ritual". Georges Balandier (1988), en particular pp. 108-118, "El derecho y el revés".
} 
conflictos que existen entre los que participan en el ritual. Ello tiene como efecto acentuar la cohesión social del sistema en el que se dan dichos conflictos. A través de las hostilidades ritualizadas entre bizuts y veteranos, se afirmaría, entonces, la aceptación común de fines y valores con respecto al sistema de enseñanza y sociocultural más amplio, en el que están insertos. Esto se refleja en las declaraciones de un informante cuando habla de "una comunidad de sufrimiento", en referencia a la dureza del sistema de prépas y Grandes Ecoles.

Sin embargo, si todos los testigos subrayan la aceptación generalizada del bizutage por parte de la mayoría de sus co-iniciandos, existen casos de insumisión total al ritual —que propongo llamar "rebelión-rechazo"- en los que se condena la práctica entera. Las quejas oficiales son notablemente escasas, pero existen, aunque rara vez conducen a un examen judicial. La prensa cita un libro - Bizut, de la Humillación en las Grandes Ecoles- escrito en 1995 por una antigua alumna de una clase preparatoria de Versailles, en el que denuncia las "prácticas de violencia, de sadismo, y de voyeurismo", sobre todo en los internados. Hubo también un caso de rechazo total por parte de un alumno de la Ecole Nationale des Arts et Métiers que ilustra la reacción sumamente represiva que produce esa actitud. Durante dos años, el alumno sufrió nuevas "humillaciones" y acabó excluido de todas las actividades de la escuela dirigidas por los estudiantes, a pesar de la ardua lucha emprendida por su padre. Como concluye la autora del libro citado, el bizutage no acepta la rebelión-rechazo y la reprime severamente. En efecto, tal actitud es considerada por los miembros del sistema de Grandes Ecoles, es decir por los iniciados, como una traición, una deserción y una transgresión. La frontera social que crea el bizutage entre los elegidos y los excluidos del sistema elitista de enseñanza superior tiene también como función "impedir que los que están dentro, del lado bueno de la línea, puedan salir, puedan rebajarse, desclasarse. Las elites [...], cuando dejan de creer en ellas mismas, cuando pierden la moral y su moral y traspasan la línea de demarcación en el mal sentido, están condenadas a la extinción" (Bourdieu 1985: 82).

La existencia de estos casos de rechazo pone de relieve el hecho más general de la aceptación de los valores del sistema. Lo que llamo "rebeliónrechazo" corresponde, en el lenguaje de Gluckman, a una actitud "revolucionaria", que cuestiona las reglas y los valores del sistema y acaba amenazándolo. En cambio, la rebelión autorizada y la inversión de normas permitida dentro del marco ritual muestran que las relaciones sociales que estructuran el sistema son muy fuertes. Si no fuera el caso, como lo subraya Gluckman, la expresión de hostilidad, de conflictos, y la inversión de valores, llegarían a hacer explotar el sistema, en lugar de favorecer su cohesión y su perpetuación. Las relaciones sociales expresadas y creadas en el bizutage son lo su- 
ficientemente fuertes para tolerar (e incluso necesitar) un gasto de energía y tiempo notable, para producir eventualmente conductas excesivas con respecto a las normas sociales (violencia, sadismo, excesos sexuales, según testigos citados por Le Monde), y para reprimir severamente el rechazo del bizutage.

Con este análisis de la rebelión dentro del ritual, podemos entender mejor por qué la práctica está tan aceptada en general, siendo muy minoritarias las reacciones de rechazo antes señaladas. Ello no impide, sin embargo, que haya casos —difíciles de cifrar- de sufrimiento verdadero producido por el bizutage, sea físico o psicológico, en los que la iniciación puede haber dejado secuelas importantes. Pero los mecanismos de consentimiento y de represión son tan fuertes que tales casos no salen fácilmente a la luz.

\section{LA PROHIBICIÓN DEL BIZUTAGE}

Ahora, al abordar el tema de la prohibición reciente del bizutage y de su represión severa, regulada en la ley de 1998, dejo el "presente etnográfico" utilizado hasta aquí para introducir la dimensión dinámica de los cambios que se producen en torno a este ritual.

La novedad introducida por la ley actual, originada en un proyecto presentado por la Ministra de Educación francesa, consiste en la prohibición completa del bizutage y no sólo de sus excesos. Dichos excesos (violencia física, atentados de tipo sexual), cuando se producían y en la medida en que se denunciaban, caían bajo el aparato judicial existente. Pero ahora es la práctica entera la que se vuelve ilegal —se considera como "envilecedora"con una represión severa en caso de no cumplimiento: "El hecho para un alumno de imponer a otro alumno o estudiante, mediante presiones de cualquier tipo, actos, actitudes o comportamientos contrarios a la dignidad de la persona humana $[. .$.$] se sanciona con una pena de seis meses de encarcela-$ miento y 50.000 francos $^{22}$ de multa". La sanción es aún mayor en caso de "particular vulnerabilidad de la víctima de tales actos". Unos años antes, ciertas asociaciones - entre otras: sindicatos de profesores, la Liga de los Derechos del Hombre- habían empezado a pedir la prohibición del bizutage, y se agruparon en un comité nacional, centralizando testimonios sobre los daños físicos y psicológicos sufridos por las víctimas de ese ritual. Si la escasez de quejas oficiales era notable, los testimonios eran suficientemente numerosos como para producir cierta movilización y alertar sobre lo que se percibía como un recrudecimiento.

Las voces que denunciaban el aspecto humillante e irracional de la práctica, subrayaban su carácter condenable en términos éticos -atentado a

\footnotetext{
${ }^{22}$ Unos 7500 Euros.
} 
la dignidad de la persona, incluso con riesgos de secuelas graves-, su aspecto anacrónico —supervivencia de un viejo "folklore" estudiantil- y su dimensión perjudicial para la enseñanza: pérdida de varias semanas de estudios, freno a la integración de estudiantes extranjeros que se asombran de la persistencia de tales prácticas consideradas "salvajes". Sin embargo, el obstáculo jurídico principal a la prohibición del ritual, antes de la ley actual, lo constituía el argumento de la aceptación del bizutage por parte de los iniciandos y su consentimiento de las prácticas a las que se sometían.

Por otra parte, varias asociaciones de antiguos alumnos protestaron en contra del proyecto de ley y muchos de mis informantes manifiestan también aquella oposición. En la historia del bizutage, de forma constante se ha producido un conflicto entre los poderes públicos que han intentado reprimir la práctica y las instituciones (Grandes Ecoles, antiguos alumnos) que defienden el bizutage en nombre de la tradición, y que han seguido practicándolo a pesar de la desaprobación oficial. Pese a ello, esas instituciones se expresan en contra de los excesos que el ritual puede producir y reconocen la necesidad de sancionar algunos actos de "desbordamiento", para los cuales consideran, empero, que el aparato de leyes existentes es suficiente.

La primera observación que el estudio del bizutage lleva a formular con respecto a este debate es la relevancia social del ritual: hace y dice algo, y este algo es importante. Tiene su "racionalidad social", en la medida en que, como traté de mostrar, constituye un medio para asegurar la reproducción de un sistema de dominación social basado en los títulos de Grandes Ecoles.

Este sistema de dominación está enmascarado por la ideología del sistema educativo, que afirma ser neutro y objetivo con respecto a las clases sociales y basar su selección únicamente en las cualidades intelectuales y académicas individuales de las personas. Esas cualidades están desigualmente repartidas, pero esa desigualdad es presentada como "natural". Al no reconocer el papel del capital cultural del medio de origen, que no sólo proporciona una preparación y una formación ante las exigencias del sistema académico, sino que además determina en buena parte las actitudes con respecto a la cultura y a los estudios; al no reconocer tampoco el papel de toda la socialización que tiene lugar antes de la escuela, el sistema educativo consigue la adhesión general de los miembros de la sociedad, que interiorizan sus criterios cómo legítimos, al percibirlos como naturales y no sociales. Esto es particularmente válido en Francia, donde la ideología de la igualdad de oportunidades para todos, a través de la escuela republicana, está fuertemente anclada en la cultura, mientras coexiste con una enseñanza superior marcadamente elitista ${ }^{23}$.

${ }^{23}$ Véase el estudio de Bourdieu y Passeron (1977). 
El propio sistema de oposiciones para entrar en las Grandes Ecoles es una buena muestra de aquella contradicción. Las pruebas son muy duras, como ya señalé; pero no sólo por ser de alto nivel intelectual, sino sobre todo debido a las capacidades psicológicas y sociales que se ponen en juego. En varias escuelas, las pruebas orales son públicas, en dos sentidos. Cualquiera puede entrar en el aula donde tiene lugar un examen oral y asistir en directo al "suplicio" que sufre el candidato. Por otra parte, un sistema de cámaras de vídeo transmite las imágenes de las pruebas individuales que están teniendo lugar en todo el edificio. En la práctica, el examen consiste en que el tribunal haga todo lo posible para confundir al candidato, desestabilizarlo, hacerle perder la confianza, para probar su capacidad de aguante y de devolver la pelota. Aunque los conocimientos académicos son un prerrequisito, están lejos de bastar para aprobar; también son necesarios la seguridad en sí mismo y el talento para responder sin alterarse a los insultos implícitos de los examinadores y a las trampas que ponen. Los estudiantes de prépa conocen de sobra las anécdotas que se cuentan sobre estas pruebas y la actitud que se espera del estudiante para que sea seleccionado. Como en la historia siguiente: uno de los examinadores le pide al público, "Por favor, traed un manojo de heno para el burro que tengo delante de mí". El candidato responde: "Puede añadir tres para mis amigos del tribunal". Este ejemplo ilustra el hecho de que las competencias que se buscan son sociales más que intelectuales, pues se basan en la superioridad y la arrogancia, en la confianza en sí mismo en cualquier contexto, en la autoafirmación y la soberbia. También pone de relieve que las atribuciones de "humillante", "vejatorio", "atentado a la dignidad de la persona", se pueden aplicar muy bien al contexto de las pruebas oficiales del sistema de Grandes Ecoles, del mismo modo que se las aplica a las pruebas del bizutage, aunque en el primer caso no haya dimensión física o corporal. Sin embargo, no faltan los casos de candidatos que acaban totalmente bloqueados, sin poder hablar, o que se echan a llorar durante las pruebas orales.

La segunda observación es que el debate que tuvo lugar acerca de la prohibición del bizutage enfrentaba a grupos y personas que tomaban postura de manera distinta con respecto al sistema de enseñanza superior en el que aquél se practicaba: por un lado, los representantes de las instituciones y las personas que han pasado por ellas, y así han conseguido un determinado éxito social (Grandes Ecoles, asociaciones de antiguos alumnos); por otro lado, los miembros de la clase política —en general formada por otro sistema un tanto distinto, con otros procesos de selección- y lo que se podría llamar las "víctimas del sistema": aquellos casos de "rebelión-rechazo" evocados antes. Estas últimas habían conseguido movilizar algunas organizaciones de defensa de los derechos de la persona, pero habían sido sometidas a me- 
didas de represión severas, pues manifestaban una contradicción desde la perspectiva del sistema: no es compatible formar parte de la elite que el sistema produce, y al mismo tiempo rechazar y denunciar una de sus prácticas más representativas. Lo que quiero indicar es la existencia de intereses sociales que están en juego mientras se defienden posturas como el derecho de la persona y la lucha contra toda forma de atentado a su dignidad. Ello resalta claramente cuando se observa que se atacaba el bizutage, pero sin relacionarlo con el sistema de Grandes Ecoles y sus características. Lo que ocurrió fue un desplazamiento del conflicto, al no reconocerse los intereses realmente en juego: no se atacaba la existencia de las Grandes Ecoles, su elitismo y su competitividad, ni el carácter humillante de su sistema de oposiciones; pero sí, paradójicamente, se quería acabar con el bizutage. La Educación Nacional y el Ministerio de Educación se encontraban en una posición implícitamente ambigua: el discurso dominante era de igualdad ante la educación, de acceso a una formación de calidad para el mayor número de estudiantes, pero la realidad social mostraba que los mayores éxitos los producía un sistema totalmente opuesto a esos valores de igualdad, como es el de las Grandes Ecoles. No era de extrañar que los defensores de este sistema se crispasen en posiciones de defensa del bizutage, presentándolo como algo inocente y lúdico.

Ahora que el bizutage está prohibido y que el Estado se ha dotado de los medios adecuados para aplicar la prohibición, las prépas tratan de organizar sustitutivos ${ }^{24}$ al ritual con el fin de asegurar la "integración" de los nuevos estudiantes; ésta vez con la participación de los profesores y de la administración, mediante, por ejemplo, seminarios centrados en actividades no estrictamente académicas, en los que se fomente la creación de lazos sociales y la transmisión de los valores propios de la institución considerada. Sin embargo, estas manifestaciones han perdido muchos de los rasgos que hacían del bizutage no sólo un rito de paso, sino una verdadera experiencia iniciática mediante la sumisión colectiva de los bizuts a los veteranos; colectivos que se definían en relación con la iniciación antes que con cualquier otro criterio.

La cuestión de cómo evolucionará el sistema de Grandes Ecoles, en ausencia de un ritual que jugaba un papel central en su reproducción y en la transmisión de sus valores, ofrece un interés teórico cierto; pero habrá que esperar algunos años para que aparezcan las consecuencias, no siempre deseadas, de un cambio de esta naturaleza, impuesto desde fuera del propio sistema. Ello recuerda, aunque a escala más pequeña, los cambios producidos en muchas sociedades primitivas cuando, con la llegada de los blancos,

${ }^{24}$ Según los testimonios más recientes que he podido conseguir. 
a los miembros de dichas sociedades se les prohibieron sus principales manifestaciones rituales: iniciaciones, tratamiento de los muertos, etc. ${ }^{25}$. Varias fueron las consecuencias: creación de rituales de sustitución, abandono progresivo de las tradiciones y desmantelamiento paulatino del sistema social antiguo con la inserción en la sociedad colonial, acompañado de nuevas relaciones, marcadas en general por la inferioridad y la explotación socioeconómica. En el caso del bizutage, se pueden desarrollar nuevas formas de lograr los mismos efectos sociales y morales, o bien, el sistema puede dejar paulatinamente de producir el tipo de elite que formaba por la falta de un ritual que participe de manera importante en ello; lo que no dejaría de tener consecuencias sobre el sistema educativo en general y la sociedad en su conjunto $^{26}$. Además, con la ola de reformas educativas que están en discusión y otros factores socioeconómicos que sin duda actuarán, la complejidad de los fenómenos en juego dificulta el hacer previsiones o incluso aislar un factor con respecto a otros.

\section{CONCLUSIÓN}

$\mathrm{Al}$ presentar este análisis antropológico del bizutage, creo haber puesto de relieve la naturaleza política del ritual. Constituye un verdadero rito de iniciación, en muchos aspectos similar a los ritos que son necesarios para el paso al estatuto de varón adulto en un gran número de sociedades "primitivas". El bizutage permite, en el fondo, la producción de una elite. Se presenta como un medio esencial para la reproducción de un sistema de estratificación social, basado en los títulos de Grandes Ecoles; no sólo para "fabricar" internamente las disposiciones individuales (adhesión a valores y representaciones) necesarias para formar parte de este sistema, sino también para afirmar la identidad y la superioridad del sistema de Grandes Ecoles, fomentar la solidaridad entre sus miembros, necesaria y fundamental para el funcionamiento del sistema y para su cohesión, y fomentar la competición entre ramas e instituciones, también necesaria y fundamental.

Espero haber mostrado cómo, en el caso estudiado, se produce una movilización de la estructura social mediante la acción ritual. Esta estructura es política; es decir, que se caracteriza por un conjunto de relaciones de poder, que el bizutage participa en realzar y perpetuar. Lo hace mediante una verdadera "transformación" del sujeto iniciado que, a través del ritual,

${ }^{25}$ Véase por ejemplo el análisis que hace Godelier de tales cambios entre los baruya, al final de La Production des grands hommes (1982).

${ }^{26}$ Recuérdese la frase de Bourdieu sobre las elites: "Cuando dejan de creer en ellas mismas [...] están condenadas a la extinción" (Bourdieu 1985: 82). 
aprende a reconocer y a adherirse a los valores jerárquicos del sistema: jerarquía entre los titulados del sistema de Grandes Ecoles y el resto de la sociedad, jerarquía interna entre ramas y escuelas, jerarquía entre lo masculino y lo femenino.

No es de extrañar, pues, que el juego político francés se haya apropiado del bizutage para prohibirlo; aunque en el debate suscitado por esta cuestión se haya ocultado en gran medida el conflicto de intereses que se halla detrás, presentándolo como una práctica extraña, aberrante y aislada del contexto en el que tiene lugar. En efecto, se ignora la contradicción esencial del sistema de educación superior en Francia: el hecho de que reproduce una jerarquía social fuerte, mientras afirma por el contrario proporcionar igualdad de oportunidades, al fundar su proceso de selección únicamente en las capacidades intelectuales individuales de los sujetos, capacidades supuestamente "naturales". Esta idea, al ser interiorizada por los sujetos sociales, permite la aceptación del sistema y por lo tanto su mantenimiento. Por ello, parece probable que la prohibición del ritual tenga en el futuro consecuencias importantes para el funcionamiento de la enseñanza superior en Francia, aunque sea difícil prever la naturaleza de los cambios que se producirán.

\section{BIBLIOGRAFÍA CITADA}

Austin, John L. 1975. Ensayos filosóficos. Madrid: Revista de Occidente.

BAlANDIER, Georges. 1988. Modernidad y poder. El desvio antropológico. Madrid: Júcar Universidad.

BeATtIE, JohN. 1972. "Creencias y valores", en Otras culturas. México: FCE.

BECKER, HOWARD. 1998. Tricks of the Trade. How to think about your research while you're doing it. Chicago: The University of Chicago Press.

BOURDIEU, PIERRE. 1979. La Distinction. Critique sociale du jugement. París: Les Editions de Minuit.

—. 1985. ¿Qué significa hablar? Madrid: Akal.

- 1998. La Domination Masculine. París: Seuil.

Bourdieu, Pierre y Jean-Claude Passeron. 1966. Los estudiantes y la cultura. Buenos Aires: Labor.

- 1977. La Reproducción. Elementos para una teoría del sistema de enseñanza. Barcelona: Editorial Laia.

Devos, RenÉ. 1998. "Le Bizutage est totalitaire". Libération, 1-10-1998.

DOUglas, Mary. 1973. Pureza y Peligro. Un análisis de los conceptos de contaminación $y$ tabui. Madrid: Siglo XXI.

Godelier, MAURICE. 1982. La Production des Grands Hommes. París: Fayard.

GLUCKMAN, MAX. 1973. Custom and conflict in Africa. Oxford: Blackwell.

LA FONTAINE, JeAN. 1984. Iniciación. Drama Ritual y conocimiento secreto. Barcelona: Lerna.

Le Monde. 1997."Les actes de bizutage seront réprimés par un nouvel article du code pénal". 4-9-1997. 
LEACH, EDMUnd. 1968. "Ritual", en David L. Sills (dir.), Enciclopedia Universal de las Ciencias Sociales. Madrid: Aguilar. Vol. 9.

- 1978. Cultura y Comunicación. La lógica de la conexión de los símbolos. Madrid: Siglo XXI

MASON, StePHEN F. 1985. Historia de las Ciencias. 3. La Ciencia del siglo XVIII. Madrid: Alianza Editorial.

- 1986. Historia de las Ciencias. 4. La Ciencia del siglo XIX. Madrid: Alianza Editorial. TURNER, VICTOR. 1980. La selva de los símbolos. Madrid: Siglo XXI.

VAN GENNEP, ARNOLD. 1986 [1909]. Los Ritos de Paso. Madrid: Taurus.

ZulaIKA, Joseba. 1989. Chivos y Soldados. La mili como ritual de iniciación. San Sebastián: Baroja. 